Review

\title{
Lignin-Based High-Performance Fibers by Textile Spinning Techniques
}

\author{
Yanhong Jin ${ }^{1,2}$, Jiaxian Lin ${ }^{1,2}$, Yu Cheng ${ }^{1,2}$ and Chunhong Lu ${ }^{1,2, *(1)}$ \\ 1 Key Laboratory of Textile Science and Technology, Ministry of Education, Donghua University, \\ Shanghai 201620, China; 2180045@dhu.edu.cn (Y.J.); 2190041@mail.dhu.edu.cn (J.L.); \\ 2190053@mail.dhu.edu.cn (Y.C.) \\ 2 College of Textiles, Donghua University, Shanghai 201620, China \\ * Correspondence: chlu@dhu.edu.cn
}

check for updates

Citation: Jin, Y.; Lin, J.; Cheng, Y.; Lu, C. Lignin-Based High-Performance Fibers by Textile Spinning Techniques. Materials 2021, 14, 3378. https:// doi.org/10.3390/ma14123378

Academic Editor: Valery Kulichikhin

Received: 14 May 2021

Accepted: 15 June 2021

Published: 18 June 2021

Publisher's Note: MDPI stays neutral with regard to jurisdictional claims in published maps and institutional affiliations.

Copyright: (c) 2021 by the authors. Licensee MDPI, Basel, Switzerland. This article is an open access article distributed under the terms and conditions of the Creative Commons Attribution (CC BY) license (https:// creativecommons.org/licenses/by/ $4.0 /)$.

\begin{abstract}
As a major component of lignocellulosic biomass, lignin is one of the largest natural resources of biopolymers and, thus, an abundant and renewable raw material for products, such as highperformance fibers for industrial applications. Direct conversion of lignin has long been investigated, but the fiber spinning process for lignin is difficult and the obtained fibers exhibit unsatisfactory mechanical performance mainly due to the amorphous chemical structure, low molecular weight of lignin, and broad molecular weight distribution. Therefore, different textile spinning techniques, modifications of lignin, and incorporation of lignin into polymers have been and are being developed to increase lignin's spinnability and compatibility with existing materials to yield fibers with better mechanical performance. This review presents the latest advances in the textile fabrication techniques, modified lignin-based high-performance fibers, and their potential in the enhancement of the mechanical performance.
\end{abstract}

Keywords: lignin; high-performance fibers; textile spinning techniques; mechanical performance

\section{Introduction}

Environmental concerns and emerging requests for sustainable and renewable resources have drawn intense attention to biopolymer-based products [1,2]. Biobased materials derived from the plants (i.e., starch, cellulose, lignin, alginate, etc.) and animals (i.e., chitin/chitosan, gelatin, wool, silk, collagen, etc.) are abundant and renewable, thereby having great potential to alleviate the current dependence on the expensive and nonrenewable petroleum-based products [3]. Moreover, biopolymers show desired properties (i.e., low density, high toughness, reasonable specific strength, good thermal properties, flexible processing procedure, biodegradability, recyclability, etc.), which make them suitable for extensive applications [4-7], such as reinforcement materials [8].

Next to cellulose, lignin is the second most abundant biopolymer in nature. Nearly 50 million tons of lignin are produced each year as a byproduct of pulp and paper industry, while only $2 \%$ is used for low- and medium-value applications. In fact, most lignin is currently utilized as low-value fuel for energy generation [9-12]. With outstanding properties (i.e., high carbon content (30-40 wt.\%) [13,14], high thermal stability, biodegradability, favorable stiffness, etc.) and cost-effectiveness (low price $\sim 3.08 \mathrm{USD} / \mathrm{kg}$ ), lignin has the potential to be developed into value-added products for various applications $[7,15,16]$. For instance, lignin has been used in polymer composites as stabilizing agents, lubricants, coatings, plasticizers, surfactants, polymer-reinforced fillers, superabsorbent hydrogels, etc. [17-23]. The development of novel materials from lignin or lignin-derived products will promote the economics of polymer composite materials, as well as possibly address lignin's disposal issue in the paper-making industry [24-26]. For polymer composite applications, an intensified focus has been directed toward the use of lignin-based carbon fibers and fiber reinforcement to potentially replace the petroleum-based plastics. In the 1960s, 
Otani et al. [27] prepared lignin-based carbon fibers with a diameter of 20-30 $\mu \mathrm{m}$ and a tensile strength (TS) of $\sim 0.8 \mathrm{GPa}$, confirming the feasibility of lignin as a raw material for carbon fibers due to its aforementioned high carbon content. Moreover, the promise of lignin as a filler for fiber reinforcement and how to make the final product completely/partially biodegradable and ecofriendly have been stressed [7,12]. The effectiveness of biobased resources for high-performance applications relies heavily upon the composition, structure, and extraction methods of the raw materials [28]. Structure features (i.e., amorphous chemical structure, low molecular weight, and broad molecular weight distribution) and poor alignment of lignin are the critical factors limiting the enhancement of mechanical properties of lignin-based fibers. To address these issues, some investigations have been conducted on fractionation or pretreatments to regulate the quality and uniformity of the lignin [29,30], on chemical methods to alter lignin structure [31,32], or on integrating lignin with other polymers to enhance strength [33].

Moreover, the importance of utilizing the textile spinning technique to obtain ligninbased high-performance fibers should be emphasized. The aim of fiber spinning is to retain the strength of the biomass and to enhance the orientation of polymer chains along the axial direction for better mechanical properties of the ultimate biobased fibers. Spinning methods (i.e., melt spinning, wet spinning, dry spinning, etc.) have their peculiar characteristics. For example, melt spinning is related to raw materials with appropriate thermal properties, narrow molecular weight distribution, and enough mobility (acceptable viscosity range of 100-450 $\mathrm{Pa} \cdot \mathrm{s}$ [34]) for the spinning process [35]. Gel-spinning typically generates high-strength fibers with few voids, but the concentrated spinning dope and low coagulation temperature required may affect the spinnability [36]. For each spinning technique, spinning conditions (i.e., temperature, speed, lignin structure, molecular weight, etc.) have great influence on the spinnability and mechanical performance of final lignin-based fibers, which should be comprehensively summarized.

Several published review articles have summarized various carbon fiber precursors [37,38], different aspects regarding lignin pretreatment [39], fiber formation [40,41], applications [40], and the graphitic structure [42], surface treatment [43] of lignin-based carbon fibers or nanofibers [13,44], and lignin's use in bulk composites [7,12]. However, incomplete information is available in the existing literature that comprehensively summarizes different textile fiber spinning techniques for fiber formation (Figure 1) of lignin-based carbon fibers and lignin-reinforced polymeric fibers potentially for composite applications and corresponding mechanical performance, which is vital for high-performance applications. Thus, this article reviews the feasibility of using lignin as an indispensable component to prepare low-cost biobased fibers including carbon fibers and lignin-reinforced polymeric fibers from various textile spinning techniques. In this review, an overview of different lignin types and corresponding structures and properties is first introduced. Moreover, recent advances regarding the spinnability and physical performance of lignin-based fibers including lignin-based carbon fibers and lignin-reinforced polymeric fibers from different spinning methods are discussed. Lastly, the review concludes with future perspectives on fabricating high-performance lignin-based fibers. 


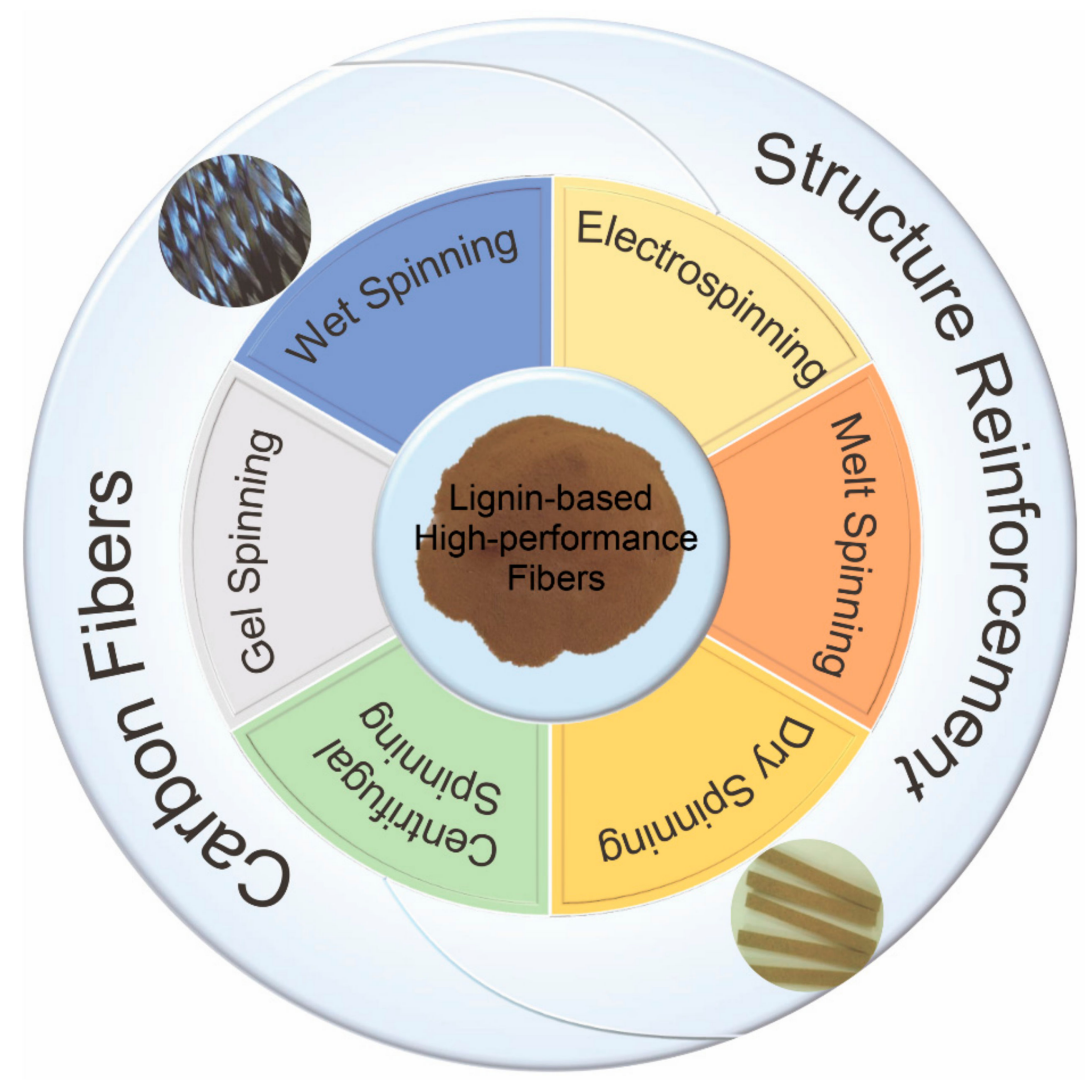

Figure 1. Diagram illustrating overview of lignin-based high-performance fibers for carbon fiber and structure reinforcement of composite (reproduced from an open-access article [45]) applications by textile spinning techniques in this review.

\section{Lignin's Structure and Properties}

Lignin is one of the main constituents in the cell walls of plants, together with cellulose and hemicellulose (Figure 2a) [46]. It is a biopolymer with highly branched polyphenolic network structures [46]. The monomers of lignin are phenyl propane units that differ in the degree of oxygen substitution on the phenyl ring (Figure 2b). The H-structure ( $p$-hydroxy phenyl) has a single hydroxyl or methoxy group, the G-structure (guaiacyl) has two such groups, and the $\mathrm{S}$-structure (syringyl) has three. Those three monomers are linked by various types of $C-O(\beta-O-4,4-O-5$, or $\alpha-O-4)$ and $C-C(\beta-5, \beta-\beta, \beta-1$, or $5-5)$ bonds (Figure 2c). The predominant linkage in the structure is $\beta-O-4$, which constitutes more than $50 \%$ of the linkage units in both softwoods and hardwoods [47]. Hydrogen bonding between adjacent carboxylic, hydroxyl, and ether groups, as well as $\pi-\pi$ interactions between aromatic moieties [48-50], accounts for the three-dimensionally (3D) branched and complex structures of lignin. Due to lignin's complex interconnected structure, the exact chemical structure and molecular weight of lignin are still unknown, and there is enormous variation in the structure depending on the sources and isolation methods [51]. Although lignin contains a large number of hydroxyl groups, it is considered more hydrophobic than carbohydrate polymers (cellulose and hemicellulose) in plants. Thus, lignin plays an important role in plants, providing mechanical support, regulating water transport, and protecting the living plants against microorganisms [52,53]. On the basis of the abovementioned structure features, lignin is regarded as a potential source of phenolic compounds to replace petroleum-based chemicals and to manufacture high-value-added chemical products [54]. 


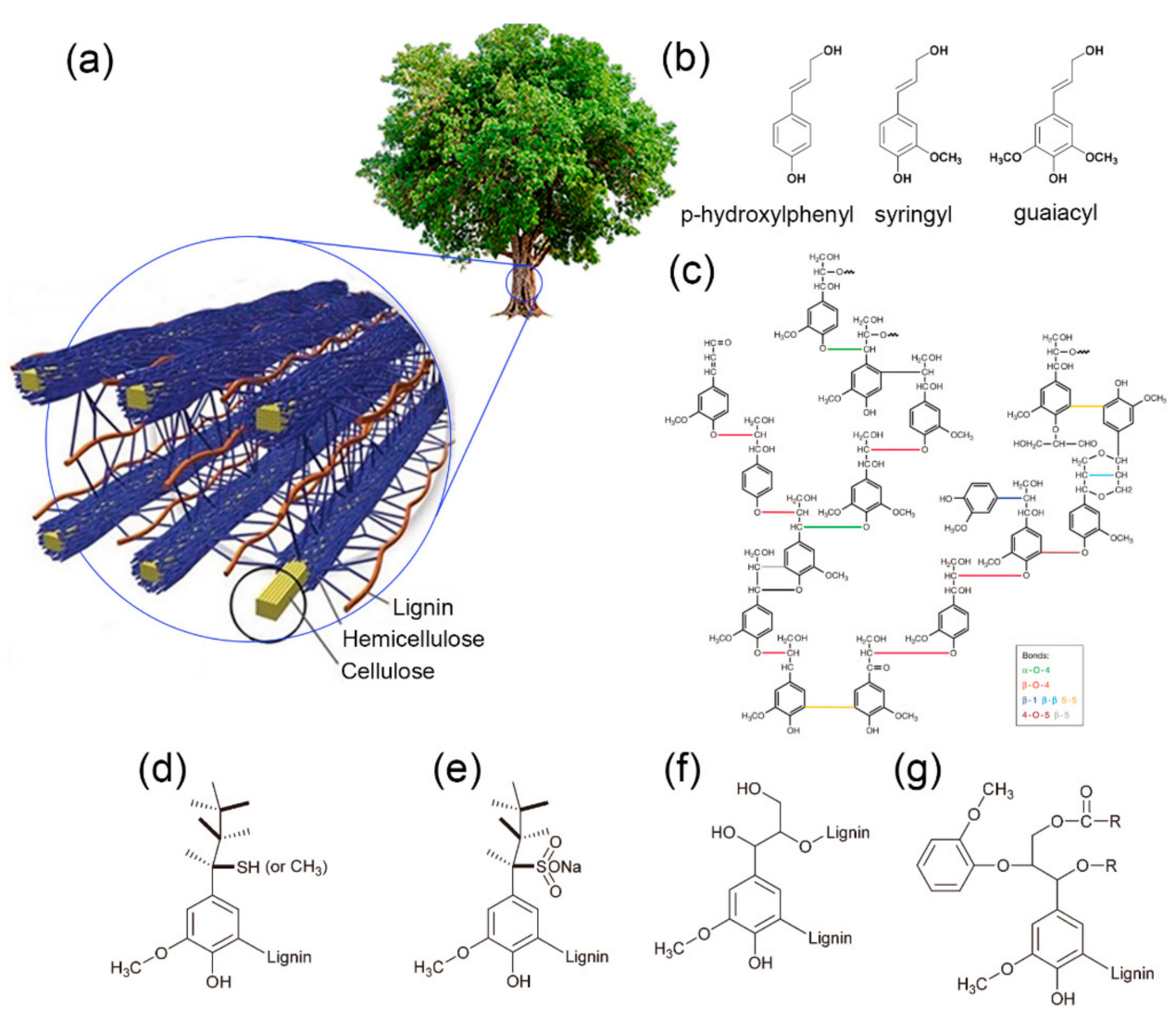

Figure 2. (a) The structure of lignocellulose biomass present in plants: highly aligned cellulose strands are surrounded by hemicellulose and lignin. (b) The chemical structure of three major monomers of lignin. (c) The general chemical structure of lignin with different $\mathrm{C}-\mathrm{O}(\beta-\mathrm{O}-4,4-\mathrm{O}-5$, or $\alpha-O-4)$ and $C-C(\beta-5, \beta-\beta, \beta-1$, or $5-5)$ linkages. Technical lignins of (d) Kraft, (e) lignosulfonate, (f) soda, and (g) organosolv lignin. (a) Reproduced with permission from [46], copyright 2011 Elsevier. (b) Reproduced with permission from [55], copyright 2015 Royal Society of Chemistry. (c) Reproduced with permission from [56], copyright 2012 Elsevier. (d-g) Reproduced with permission from [52], copyright 2016 Royal Society of Chemistry.

In general, wood-derived lignin can be categorized into hardwood or softwood lignin according to its source. Lignin in softwood contains almost 90\% G-units [54], whereas hardwood lignin is mainly composed of G- and S-units, with higher S-unit proportions; it demonstrates thermoplastic characteristics with a definable melt-processable temperature [57]. Moreover, softwood and hardwood lignins demonstrate a huge difference in how the monomers are connected. Compared with hardwood lignin, softwood lignin has more resistant $C-C(\beta-\beta, \beta-5, \beta-1$, and $5-5)$ bonds and a lower content of ether bonds because the $C_{5}$ positions of $G$-units in softwood lignin tend to involve a coupling reaction to form resistant linkages, whereas those in S-units are sterically inhibited due to the additional methoxy group $\left(\mathrm{OCH}_{3}\right)[58,59]$. In other words, softwood lignin readily forms dibenzodioxocin [60], while hardwood lignin tends to form a more linear structure than softwood lignin due to the excessive number of S-units in the structure [57]. The difference in chemical structures of softwood and hardwood lignins leads to remarkably different softening temperatures, which are $138-160{ }^{\circ} \mathrm{C}$ for softwood lignin and $110-130{ }^{\circ} \mathrm{C}$ for hardwood lignin [61]. The softening temperature of lignin is defined as the temperature at which the internal friction of lignin is at a maximum value [62]. At the softening temperature or glass transition temperature $\left(\mathrm{T}_{\mathrm{g}}\right)$, polymers achieve sufficient energy to decrease the mutually attractive forces, such that they become rubbery or plastic to a greater or lesser degree [63]. It is this softening behavior of lignin at elevated temperature that has inspired research 
efforts to develop lignin-based high-performance fibers to replace currently ubiquitous petroleum-based high-performance fibers.

Lignin can also be classified into four different types of technical lignin, according to the pulping process: Kraft, lignosulfonate, soda, and organosolv lignin. Firstly, most lignin is extracted by the Kraft process, which accounts for the largest volume among all types of lignin. In this process, lignin's linkages or covalent attachments to surrounding materials of cellulose and hemicellulose are degraded in the presence of white liquor, which is an aqueous solution of sodium hydroxide $(\mathrm{NaOH})$ and sodium sulfide $\left(\mathrm{Na}_{2} \mathrm{~S}\right)$ mixture. Thus, the Kraft process fractures lignin into smaller and water-soluble molecules, allowing further fragmentation of lignin as the linkages between the phenylpropane units are cleaved [47]. Structurally, Kraft lignin has aliphatic thiol groups (Figure 2d), which make the biopolymer hydrophobic, and it contains sulfur (1-2 wt.\%) [46] after the Kraft pulping process. Second, the sulfite process is quite similar to the Kraft process, except that the medium of the former is acidic. In the sulfite pulping process, salts (such as sodium $\left(\mathrm{Na}^{+}\right)$, potassium $\left(\mathrm{K}^{+}\right)$, ammonium $\left(\mathrm{NH}^{4+}\right)$, calcium $\left(\mathrm{Ca}^{2+}\right)$, and magnesium $\left(\mathrm{Mg}^{2+}\right)$ counterions) of sulfurous acid aqueous solution, sulfites $\left(\mathrm{SO}_{3}{ }^{2-}\right)$, or bisulfites $\left(\mathrm{HSO}_{3}{ }^{2-}\right)$ degrade and sulfonate the lignin by replacing the hydroxyl group with a sulfonate group. As a result, lignin is solubilized and separated from the cellulose in non-precipitated form. This process can be performed in the $\mathrm{pH}$ range of $2-12$, depending on the cationic counterions. In most cases, this process is completed in acidic conditions with calcium or magnesium counterions [64]. The final product of lignin is in the form of lignosulfonates $[65,66]$. The use of sulfurous acid in the pulping process yields sulfonate groups $\left(-\mathrm{SO}_{3}\right)$ in the chemical structure of lignosulfonates (Figure 2e), making them water-soluble over a wide range of $\mathrm{pH}$ values [46]. Thirdly, soda lignin undergoes a similar cooking process to Kraft lignin, except that soda pulping does not contain $\mathrm{Na}_{2} \mathrm{~S}$ in the alkali medium [67]. Due to the absence of a strong nucleophile, depolymerization of lignin with only alkaline $(\mathrm{NaOH})$ is less efficient [67] in comparison with the Kraft process. This soda pulping process is a predominant method for chemical pulping of non-wood species such as bagasse, wheat straw, hemp, kenaf, and sisal [68]. With no sulfur (Figure 2f) and little hemicellulose contaminating its structure, soda lignin can be used directly without purification. These features make soda lignin more suitable for chemical modification in order to be used in other value-added applications. Lastly, organosolv pulping is a process that uses organic solvents (i.e., acetic acid, formic acid, ethanol, peroxiorganic acids, etc.) and water as the cooking liquid for the wood chips [69]. Organosolv lignin, like soda lignin, has little modification of structure after being recovered from the organosolv pulping process. Organosolv lignin has a lower softening temperature $\left(90-110^{\circ} \mathrm{C}\right)$ than soda lignin $\left(140{ }^{\circ} \mathrm{C}\right)$ [52]. The former contains fewer aliphatic hydroxyl groups (Figure $2 \mathrm{~g}$ ) than soda lignin. This is due to the organosolv process involving the depolymerization of lignin by acid-catalyzed cleavage of $\beta$-ether linkages [70]. The produced lignin is abundant in $\beta$-ether linkages, while the fragments can condense back to higher-molecular-weight polymers at lower $\mathrm{pH}$ via the elimination of $\mathrm{CH}_{2} \mathrm{OH}$ [71]. Organosolv lignin is in a relatively pure state, which is ideal for direct usage to manufacture different products.

\section{Mechanical Performance of Lignin-Based Fibers}

Textile fiber spinning is a typical process that involves the orientation of polymer melts or solutions to align the macromolecules and as a result increases the strength of the material [72]. In the textile industry, fiber spinning techniques are widely used in the production of synthetic and regenerated fibers, and they generally include conventional spinning techniques (such as melt spinning, wet spinning, dry spinning, and gel spinning), as well as electrospinning and centrifugal spinning. Conventional fiber spinning techniques often yield polymeric fibers with diameters in the micrometer range [73]. Electrospinning and centrifugal spinning are capable of consistently producing fibers with diameters down to several nanometers $[74,75]$. 
In general, lignin is usually structurally modified, blended with other thermoplastic polymers, or added as a reinforcement material to enhance the fiber performance. In this section, the efforts made to improve the spinnability and mechanical performance of ligninbased high-performance fibers obtained via various spinning techniques are discussed.

\subsection{Lignin-Based Carbon Fibers}

As one type of high-performance fiber, carbon fibers are used as reinforcement in various composites [76]. Among the common precursors for commercially available carbon fibers, petroleum-based polyacrylonitrile (PAN) is the dominant precursor, which is quite expensive and accounts for more than $50 \%$ of the overall cost of carbon fiber production. Other precursors, such as pitch and rayon, are either too expensive or yield carbon fibers with less satisfactory mechanical properties [77]. Lignin has drawn intense attention as a potential carbon fiber precursor due to its natural abundance and high carbon yield with its unique aromatic structure. Lignin-based carbon fibers have extremely low cost and long-term sustainability if precursor-grade lignin is successfully converted into fibers.

\subsubsection{Melt-Spun Lignin-Based Carbon Fibers}

Melt spinning of lignin-based fibers has drawn intense attention since the 1990s [33,78-85]. This high-speed process can potentially produce low-cost lignin-based carbon fiber precursors. Generally, melt-spun lignin-based fibers are achieved by converting lignin powders or pellets into fibers or filaments above the softening temperature, and then quenching them in cold air before fibers are collected at high speed (Figure 3a). The mechanical properties of melt-spun lignin fibers mainly depend on different factors such as the source of lignin (molecular weight, softening temperature, molecular structure), degree of crystallinity, and orientation of the fiber, which are closely related to processing parameters of the melt spinning process (i.e., heating temperature, extrusion speed, take-up speed, etc.) [86,87].

It should be noted that most lignins have small molecular weight and no melting point due to the amorphous chemical structure; thus, they often decompose when heated at a temperature higher than $200-250{ }^{\circ} \mathrm{C}$ [88], which greatly affects the processing temperature. The difference between the extrusion speed and collecting speed is vital in increasing the degree of molecular orientation and percentage crystallinity, which contribute to the mechanical performance of the fibers [89]. However, lignin's amorphous, three-dimensionally branched structure prevents the formation of crystals in the fiber spinning process, which may hinder fiber strength. The difference in lignin chemical structure due to source also affects melt processability. For instance, the higher softening temperature of softwood lignin often leads to poorer spinnability by melt spinning, thereby requiring additional treatments such as chemical modification or blending with other polymers for fiber processing. Even though hardwood lignin is generally melt-processable, the ratio between S- and G-units should be carefully tuned for efficient melt spinning. Moreover, it is difficult to stabilize melt-spun lignin precursor fibers to yield low-cost carbon fibers via thermo-oxidation since they are prone to partially fuse during the stabilization and carbonization process [84]. This is mainly due to the melt-spun lignin-based precursor fibers lacking sufficient chemical reactivity to be crosslinked during the stabilization process before undergoing the ultimate high-temperature carbonization process. As a result, melt-spun lignin-based carbon fibers have structural defects and inferior mechanical performance to PAN-based carbon fibers [31]. 
(a)

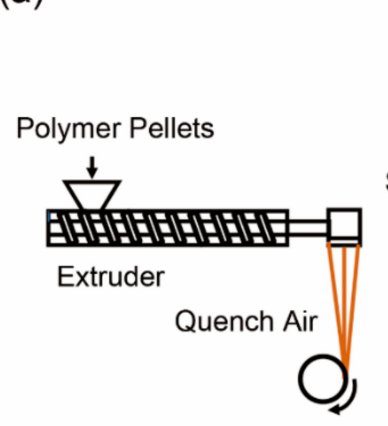

Fiber Take-up (b)

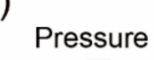

(c)

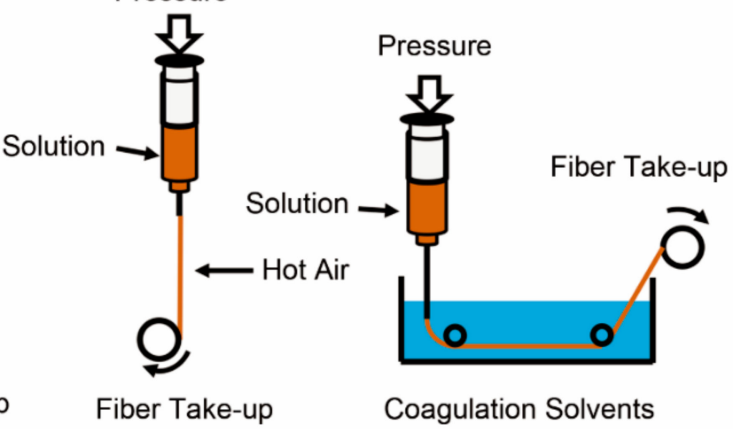

(d)

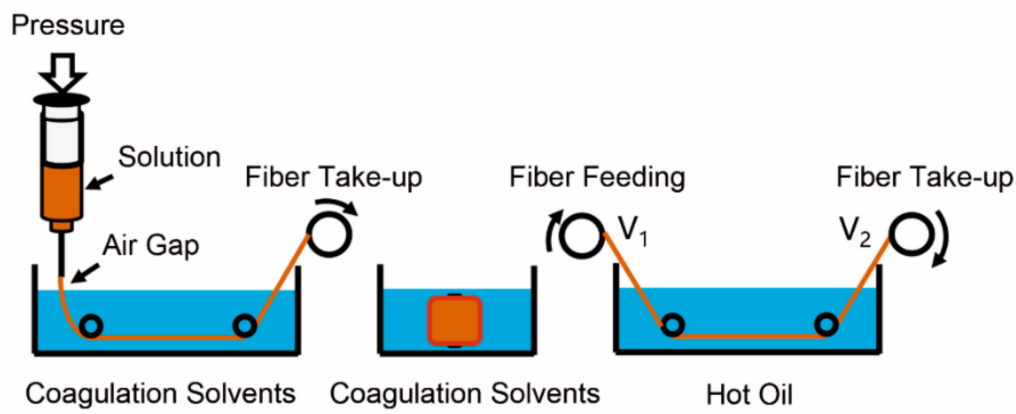

(e)

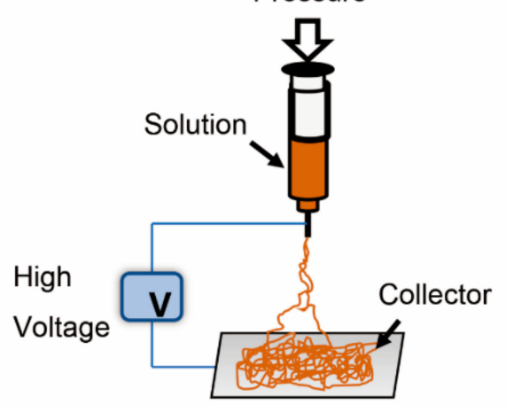

(f)

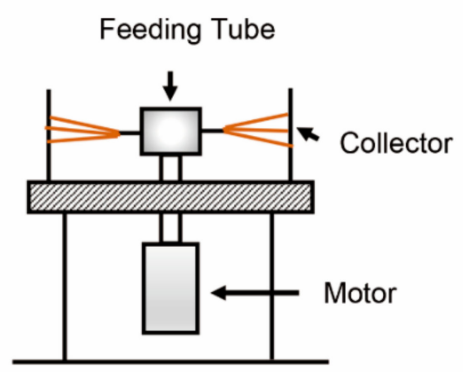

Figure 3. Simplified processes for (a) melt spinning, (b) dry spinning, (c) wet spinning, (d) gel spinning, (e) electrospinning, and (f) centrifugal spinning.

To improve fiber spinnability, it is of great importance to modify lignin to achieve some extent of molecular rotation and adequate material fluidity for melt-spun lignin-based fibers [78]. Lignin modifications could reduce the amount of hydroxyl groups or crosslinks that resist flow to make lignin a more flexible polymer at high temperatures of the melt spinning process [78]. Another commonly used method to improve spinnability is to blend lignin with other polymers (i.e., polyethylene (PE), polypropylene (PP), poly(ethylene oxide) (PEO), poly(ethylene terephthalate) (PET), etc.), and later melt-spin the blend into fibers with no porous structure but highly rough surfaces [90]. Unfortunately, poor compatibility of lignin and polymer in melt spinning becomes the main obstacle that hinders the enhancement of the composite fiber's mechanical properties. Table 1 summarizes the characteristics of melt-spun lignin-based carbon fibers from the reported literature, which are presented in detail below. 
Table 1. Literature summary of melt-spun lignin-based carbon fibers.

\begin{tabular}{|c|c|c|c|c|c|c|}
\hline \multirow{2}{*}{$\begin{array}{l}\text { Modification/ } \\
\text { Fractionation }\end{array}$} & \multirow{2}{*}{$\begin{array}{l}\text { Lignin/Polymer } \\
\text { (Mass Ratio) and Reference }\end{array}$} & \multirow{2}{*}{$\begin{array}{l}\text { Processing } \\
\text { Temperature }\left({ }^{\circ} \mathrm{C}\right)\end{array}$} & \multirow{2}{*}{$\begin{array}{l}\text { Thermal Treatment } \\
\text { Stabilization/Carbonization }\end{array}$} & \multirow{2}{*}{$\begin{array}{l}\text { Diameter } \\
(\mu \mathrm{m})\end{array}$} & \multicolumn{2}{|c|}{ Mechanical Properties } \\
\hline & & & & & $\begin{array}{l}\text { TS } \\
\text { (MPa) }\end{array}$ & $\begin{array}{l}\mathrm{TM} \\
(\mathrm{GPa})\end{array}$ \\
\hline \multirow{11}{*}{ Unmodified lignin } & Hardwood Kraft lignin [82] & $195-228$ & $\begin{array}{l}250^{\circ} \mathrm{C}, 12 \sim 180^{\circ} \mathrm{C} / \mathrm{h}, 1 \mathrm{~h} \text {, air } \\
1000^{\circ} \mathrm{C}, 180^{\circ} \mathrm{C} / \mathrm{h} \text {, nitrogen }\end{array}$ & $46 \pm 8$ & $422 \pm 80$ & $40 \pm 11$ \\
\hline & Hardwood Kraft lignin/PEO (97/3) [82] & $189-228$ & $\begin{array}{l}250^{\circ} \mathrm{C}, 12 \sim 180^{\circ} \mathrm{C} / \mathrm{h}, 1 \mathrm{~h} \text {, air } \\
1000^{\circ} \mathrm{C}, 180^{\circ} \mathrm{C} / \mathrm{h} \text {, nitrogen }\end{array}$ & $33 \pm 2$ & $458 \pm 97$ & $59 \pm 8$ \\
\hline & Pyrolytic lignin [91] & $105 / 125$ & $\begin{array}{l}250^{\circ} \mathrm{C}, 0.5^{\circ} \mathrm{C} / \mathrm{min}, 1 \mathrm{~h} \text {, air } \\
1000^{\circ} \mathrm{C}, 3^{\circ} \mathrm{C} / \mathrm{min}, 1 \mathrm{~h} \text {, nitrogen }\end{array}$ & $49 \pm 2$ & $370 \pm 38$ & $36 \pm 1$ \\
\hline & Organosolv lignin [92] & 210 & $\begin{array}{l}250^{\circ} \mathrm{C}, 0.5^{\circ} \mathrm{C} / \mathrm{min}, 1 \mathrm{~h} \text {, air } \\
1000^{\circ} \mathrm{C}, 3^{\circ} \mathrm{C} / \mathrm{min}, 1 \mathrm{~h} \text {, nitrogen }\end{array}$ & $14 \pm 1$ & $355 \pm 53$ & $39.1 \pm 13.3$ \\
\hline & Hardwood Kraft lignin/PET (75/25) [33] & $130-240$ & $\begin{array}{l}250^{\circ} \mathrm{C}, 0.2-3{ }^{\circ} \mathrm{C} / \mathrm{min}, 1 \mathrm{~h} \text {, air } \\
1000^{\circ} \mathrm{C}, 3^{\circ} \mathrm{C} / \mathrm{min} \text {, nitrogen }\end{array}$ & $34 \pm 5$ & 703 & 94 \\
\hline & Hardwood Kraft lignin/PP (87.5/12.5) [93] & $130-240$ & $\begin{array}{l}250^{\circ} \mathrm{C}, 0.2-3{ }^{\circ} \mathrm{C} / \mathrm{min}, 1 \mathrm{~h} \text {, air } \\
1000^{\circ} \mathrm{C}, 3^{\circ} \mathrm{C} / \mathrm{min} \text {, nitrogen }\end{array}$ & $44 \pm 5$ & 437 & 54 \\
\hline & Lignin/PLA (80/20) [80] & $220-240$ & $\begin{array}{l}280^{\circ} \mathrm{C}, 0.25^{\circ} \mathrm{C} / \mathrm{min}, 1 \mathrm{~h} \text {, air } \\
1000^{\circ} \mathrm{C} \text {, nitrogen }\end{array}$ & $30-60$ & 159.2 & 11.6 \\
\hline & Organosolv yellow polar lignin [70] & $\mathrm{N} / \mathrm{A}$ & $\begin{array}{l}250{ }^{\circ} \mathrm{C}, 0.05^{\circ} \mathrm{C} / \mathrm{min}, 30 \mathrm{~min} \text {, air } \\
\text { Stepwise: } 600{ }^{\circ} \mathrm{C}, 3{ }^{\circ} \mathrm{C} / \mathrm{min}, 5 \mathrm{~min} \text {; } \\
1000^{\circ} \mathrm{C}, 5^{\circ} \mathrm{C} / \mathrm{min}, 15 \mathrm{~min} \text {, itrogen }\end{array}$ & $17.1 \pm 1.59$ & $544 \pm 96$ & $36.5 \pm 2.81$ \\
\hline & $\begin{array}{l}\text { Alcell organosolv hardwood lignin/TPU } \\
(50 / 50)[94]\end{array}$ & $155 / 180 / 190 / 180$ & $\begin{array}{l}250^{\circ} \mathrm{C}, 0.1^{\circ} \mathrm{C} / \mathrm{min}, 1 \mathrm{~h} \text {, air } \\
1000^{\circ} \mathrm{C}, 10^{\circ} \mathrm{C} / \mathrm{min}, 0.5 \mathrm{~h} \text {, nitrogen }\end{array}$ & $31 \pm 2$ & $1100 \pm 100$ & $80 \pm 10$ \\
\hline & $\begin{array}{l}\text { Organosolv lignin from yellow } \\
\text { poplar/organosolv lignin from switchgrass } \\
(85 / 15)[95]\end{array}$ & 180 & $\begin{array}{l}250^{\circ} \mathrm{C}, 0.05,0.1,0.2 \text { and } 0.5^{\circ} \mathrm{C} / \mathrm{min} \text {, } \\
30 \mathrm{~min} \text {, air } \\
\text { Stepwise: } 600{ }^{\circ} \mathrm{C}, 3{ }^{\circ} \mathrm{C} / \mathrm{min}, 5 \mathrm{~min} \text {; } \\
1000^{\circ} \mathrm{C}, 5^{\circ} \mathrm{C} / \mathrm{min}, 15 \mathrm{~min} \text {, nitrogen }\end{array}$ & $15.7 \pm 1.1$ & $747 \pm 208$ & $41.8 \pm 3.9$ \\
\hline & $\begin{array}{l}\text { Softwood Kraft lignin/hardwood Kraft lignin } \\
(90 / 10)[96]\end{array}$ & $140-250$ & $\begin{array}{l}250{ }^{\circ} \mathrm{C}, 0.2^{\circ} \mathrm{C} / \mathrm{min}, 1 \mathrm{~h} \text {, air } \\
\text { Stepwise: } 600{ }^{\circ} \mathrm{C}, 1^{\circ} \mathrm{C} / \mathrm{min} ; 1000{ }^{\circ} \mathrm{C} \text {, } \\
3{ }^{\circ} \mathrm{C} / \mathrm{min} \text {, nitrogen }\end{array}$ & 21.4 & $\mathrm{~N} / \mathrm{A}$ & $\mathrm{N} / \mathrm{A}$ \\
\hline $\begin{array}{l}\text { Fractionation with methanol; } \\
\text { acetylation }\end{array}$ & Modifed organosolv lignin [97] & 130 & $\begin{array}{l}250^{\circ} \mathrm{C}, 0.1^{\circ} \mathrm{C} / \mathrm{min}, 1 \mathrm{~h} \text {, air } \\
1000^{\circ} \mathrm{C}, 3^{\circ} \mathrm{C} / \mathrm{min}, 1 \mathrm{~h} \text {, argon }\end{array}$ & $39.1 \pm 5.4$ & $454 \pm 98$ & $62 \pm 14$ \\
\hline
\end{tabular}


Table 1. Cont.

\begin{tabular}{|c|c|c|c|c|c|c|}
\hline \multirow{2}{*}{$\begin{array}{l}\text { Modification/ } \\
\text { Fractionation }\end{array}$} & \multirow{2}{*}{$\begin{array}{l}\text { Lignin/Polymer } \\
\text { (Mass Ratio) and Reference }\end{array}$} & \multirow{2}{*}{$\begin{array}{l}\text { Processing } \\
\text { Temperature }\left({ }^{\circ} \mathrm{C}\right)\end{array}$} & \multirow{2}{*}{$\begin{array}{l}\text { Thermal Treatment } \\
\text { Stabilization/Carbonization }\end{array}$} & \multirow{2}{*}{$\begin{array}{l}\text { Diameter } \\
(\mu \mathrm{m})\end{array}$} & \multicolumn{2}{|c|}{ Mechanical Properties } \\
\hline & & & & & $\begin{array}{l}\text { TS } \\
\text { (MPa) }\end{array}$ & $\begin{array}{l}\mathrm{TM} \\
(\mathrm{GPa})\end{array}$ \\
\hline Repolymerization & Repolymerized pyrolytic lignin [98] & $115-120$ & $\begin{array}{l}280^{\circ} \mathrm{C}, 0.3^{\circ} \mathrm{C} / \mathrm{min}, 1 \mathrm{~h} \text {, air } \\
1000^{\circ} \mathrm{C}, 3^{\circ} \mathrm{C} / \mathrm{min}, 1 \mathrm{~h} \text {, argon }\end{array}$ & $29-50$ & $855 \pm 159$ & $85 \pm 37$ \\
\hline Hydrogenation & Modidified steam-exploded lignin [78] & $155-180$ & $\begin{array}{l}210^{\circ} \mathrm{C}, 0.5-2{ }^{\circ} \mathrm{C} / \mathrm{min} \text {, air } \\
1000^{\circ} \mathrm{C}, 5^{\circ} \mathrm{C} / \mathrm{min}, 20 \mathrm{~min} \text {, nitrogen }\end{array}$ & $7.6 \pm 2.7$ & $660 \pm 230$ & $40.7 \pm 6.3$ \\
\hline Phenolyzation & Modidified steam-exploded lignin [85] & $155-180$ & $\begin{array}{l}210^{\circ} \mathrm{C}, 0.5-2^{\circ} \mathrm{C} / \mathrm{min} \text {, air } \\
1000^{\circ} \mathrm{C}, 5^{\circ} \mathrm{C} / \mathrm{min}, 20 \mathrm{~min} \text {, nitrogen }\end{array}$ & $\mathrm{N} / \mathrm{A}$ & 455 & $\mathrm{~N} / \mathrm{A}$ \\
\hline $\begin{array}{l}\text { Stepwise: acrylation, } \\
\text { acetylation, and RAFT } \\
\text { polymerization }\end{array}$ & Modified red oak lignin bio-oil [99] & $25-280$ & $\begin{array}{l}250^{\circ} \mathrm{C}, 7^{\circ} \mathrm{C} / \mathrm{min} \text {, air } \\
1000^{\circ} \mathrm{C}, 3^{\circ} \mathrm{C} / \mathrm{min}, 1 \mathrm{~h} \text {, argon }\end{array}$ & 5.1 & 1700 & 182 \\
\hline $\begin{array}{l}\text { Fractionation with acetic } \\
\text { acid }(\mathrm{AcOH})\end{array}$ & Fractionated softwood acetic acid lignin [100] & $\mathrm{N} / \mathrm{A}$ & $\begin{array}{l}250^{\circ} \mathrm{C}, 0.5^{\circ} \mathrm{C} / \mathrm{min}, 1 \mathrm{~h} \text {, air } \\
1000^{\circ} \mathrm{C}, 3^{\circ} \mathrm{C} / \mathrm{min} \text {, nitrogen }\end{array}$ & $84 \pm 15$ & $26.4 \pm 3.1$ & $3.59 \pm 0.43$ \\
\hline Butyration & Butyrated lignin/PLA $(75 / 25)[83,101]$ & 180 & $\begin{array}{l}250^{\circ} \mathrm{C}, 0.25^{\circ} \mathrm{C} / \mathrm{min}, 5 \mathrm{~h} \text {, oxygen } \\
1000^{\circ} \mathrm{C}, 33^{\circ} \mathrm{C} / \mathrm{min} \text {, nitrogen }\end{array}$ & $122 \pm 29$ & N/A & $1.94 \pm 0.11$ \\
\hline Grafting with PEG & PEG grafted with softwood lignin [103] & $145-172$ & $\begin{array}{l}250^{\circ} \mathrm{C}, 0.1-0.5^{\circ} \mathrm{C} / \mathrm{min}, 1 \mathrm{~h} \text {, air } \\
1000^{\circ} \mathrm{C}, 3^{\circ} \mathrm{C} / \mathrm{min}, 1 \mathrm{~h} \text {, nitrogen }\end{array}$ & $10.4 \pm 1.3$ & $457 \pm 188$ & $26.2 \pm 13.3$ \\
\hline $\begin{array}{l}\text { Hydroxypropyl } \\
\text { modification }\end{array}$ & $\begin{array}{l}\text { Hydroxypropyl modified kraft hardwood } \\
\text { lignin/TPU (50/50) [94] }\end{array}$ & $175 / 190 / 200 / 190$ & $\begin{array}{l}250{ }^{\circ} \mathrm{C}, 0.1^{\circ} \mathrm{C} / \mathrm{min}, 1 \mathrm{~h} \text {, air } \\
1000^{\circ} \mathrm{C}, 10^{\circ} \mathrm{C} / \mathrm{min}, 0.5 \mathrm{~h} \text {, nitrogen }\end{array}$ & $30 \pm 1$ & $800 \pm 100$ & $66 \pm 10$ \\
\hline Grafting with CNTs & $\begin{array}{l}\text { CNTs grafted with lignin (CNTs-g-L) } \\
(0.5 / 99.5) \text { [79] }\end{array}$ & 225 & $\begin{array}{l}280^{\circ} \mathrm{C}, 0.25^{\circ} \mathrm{C} / \mathrm{min}, 1 \mathrm{~h} \text {, air } \\
1000^{\circ} \mathrm{C} \text {, nitrogen }\end{array}$ & N/A & 289.3 & 18 \\
\hline
\end{tabular}

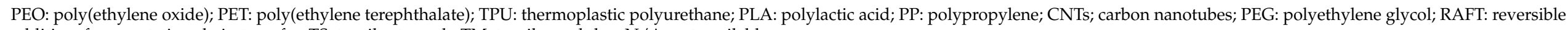
addition-fragmentation chain-transfer; TS: tensile strength; TM: tensile modulus; N/A: not available 


\section{Structurally Modified Melt-Spun Lignin-Based Carbon Fibers}

Kadla et al. [82] first reported the production of lignin-based carbon fibers from a commercially available hardwood Kraft lignin by melt spinning with no modification. The obtained carbon fibers had relatively low mechanical performance of $422 \mathrm{MPa}$ for tensile strength (TS) and of $40 \mathrm{GPa}$ for tensile modulus (TM). Generally, it is easier to meltspin hardwood lignin than softwood lignin due to the difference in chemical structures as mentioned above. In detail, softwood lignin contains more hydroxyl groups than hardwood lignin, which allows the former to easily crosslink via intramolecular interactions and lose fluidity at high temperature of the melt spinning process. To essentially enhance the spinnability and mechanical performance of lignin-based fibers with altered lignin structure, several common strategies may be used.

One strategy is to increase lignin's molten fraction by modifying its molecular weight. By investigating the influence of molecular weight and fusible fractions on the spinnability of softwood lignin-based melt-spun fibers, it was shown that the weight-averaged molecular weight $\left(\mathrm{M}_{\mathrm{w}}\right)$ should be less than 3,200 Da or the fusible fraction should be $\sim 58.2 \%$ to achieve molten lignin for melt spinning [100]. In most cases of the melt-spun lignin fibers, lignin purification and fractionation, by ultrafiltration [96], pH-fractionation [104], and solvent extraction $[70,97,105]$, are used to obtain lignin with high thermal mobility and improved performance. Essentially, purification and fractionation [106-108] can isolate a lower-molecular-weight part (and correspondingly a lower $\mathrm{T}_{\mathrm{g}}$ ) of lignin for better processability by melt spinning. For instance, a corn-stover lignin fractionated with methanol had significantly lower $\mathrm{M}_{\mathrm{w}}(1,200 \mathrm{Da})$ and polydispersity index $(\mathrm{PDI}=1.89)$ than raw lignin (3,263 Da and 2.91, respectively) [97]. Although low-molecular-weight lignin facilitates the melt spinning process at low temperature, it causes fiber fusion problems in the stabilization process due to its low $\mathrm{T}_{\mathrm{g}}$. Thus, the fractionated lignin or low-molecular-weight lignin were thermally treated to allow repolymerization [98] to increase thermal stability and then acetylated to yield melt-spun carbon fiber with TS $=0.45 \mathrm{GPa}$ and TM $=62 \mathrm{GPa}$, respectively [97]. Moreover, thermal treatment of lignin before spinning was used to achieve pyrolytic lignin with low molecular weight to facilitate melt spinning and to maintain fiber integrity during the stabilization and carbonization processes [91]. The resulting carbon fibers had relatively low $\mathrm{TS}=370 \mathrm{MPa}$ and $\mathrm{TM}=36 \mathrm{GPa}$ due to large fiber diameter $(49 \mu \mathrm{m})$ and voids. Furthermore, pyrolytic lignin recovered from hardwood by a phenolic bio-oil was catalytically repolymerized to yield suitable molecular weight for melt-spinnable precursor fibers and resulting carbon fibers with TS $=850 \mathrm{MPa}$ and TM $=85 \mathrm{GPa}$ [98]. Ideally, lignin-based carbon fiber precursors should have a high molecular weight and low PDI to achieve structural uniformity [41] and good mechanical performance. However, this contradicts with the need for the good processability of melt spinning with low-molecular-weight lignin. Thus, selection of low-molecular-weight lignin often facilitates fiber processing but yields lignin-based carbon fibers with only moderate mechanical performance.

Another important strategy is to chemically modify lignin's structure to allow fluidity at the high-temperature of melt spinning. The most commonly used chemical modification methods including esterification [109], acetylation [110], and butyration [93] (Figure 4), while other methods (i.e., hydrogenolysis, phenolysis, solvolysis) are also used to yield modified lignin. Sudo et al. [78] reported hydrogenated steam-exploded lignin. Structurally, the alkaline hydrolysis of lignin involved the cleavage of alkyl-aryl ether bonds and formation of ethylene bridges $(-\mathrm{C}=\mathrm{C}-$ ) between aromatic rings, as well as the reduction of hydroxyl groups $(-\mathrm{OH})$ and removal of methylol groups $\left(-\mathrm{CH}_{2} \mathrm{OH}\right)$. With a vacuum treatment at $300-350{ }^{\circ} \mathrm{C}$, the melt viscosity of hydrogenated lignin was improved to facilitate the melt spinning process. The carbon fibers prepared from this modified lignin exhibited a diameter of $7 \mu \mathrm{m}$, a TS of $\sim 660 \mathrm{MPa}$, and Young's modulus of $\sim 40.7 \mathrm{GPa}$, but a low yield $(<20 \%)$. Sudo et al. [85] further obtained melt-spun phenolated steam-exploded lignin as carbon fiber precursors. This alternative modification method was developed because of its lower cost and higher yield $(>40 \%)$ than hydrogenated lignin. Lignin and phenols with alkyl groups were reacted at $180-300^{\circ} \mathrm{C}$ for $2-5 \mathrm{~h}$ in the presence of a catalyst. 
Crosslinks between lignin aromatic groups were reduced, and the thermal viscosity of lignin was increased to enhance the melt spinnability of lignin with a lower softening temperature range of $150-190^{\circ} \mathrm{C}$. However, the relationship between the thermal properties of modified lignin and the degree of phenol substitution was not revealed. The resulting carbon fiber displayed a TS of $\sim 455 \mathrm{MPa}$, which was worse than that of hydrogenated lignin. Softwood lignin obtained by solvolysis of wood chips using polyethylene glycol (PEG) and sulfuric acid had good flow properties for melt spinning due to the PEG moiety linked to the lignin structure [103]. However, the stabilization of the precursor fibers was difficult, and the resulting carbon fibers (fiber diameter $\sim 10 \mu \mathrm{m})$ had a low TS $(\sim 457 \mathrm{MPa})$ and TM ( 27 GPa) due to the porous and flabby structure of the fibers.

(a)

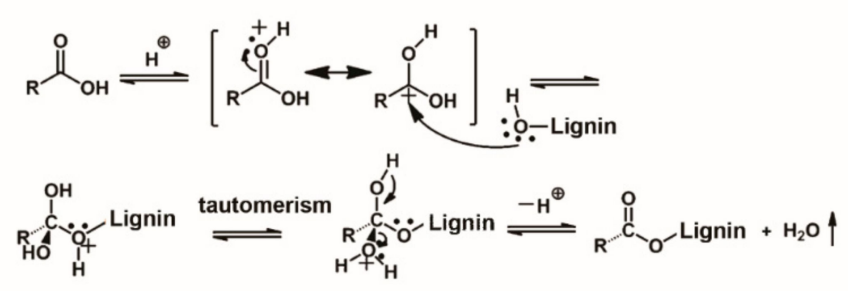

(b)

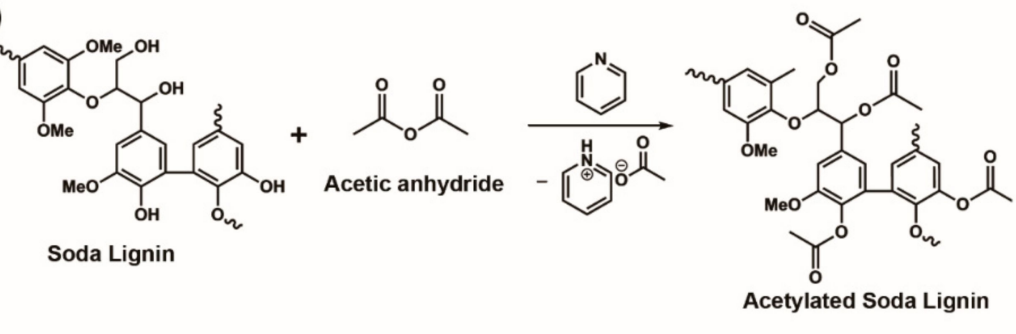

(c)

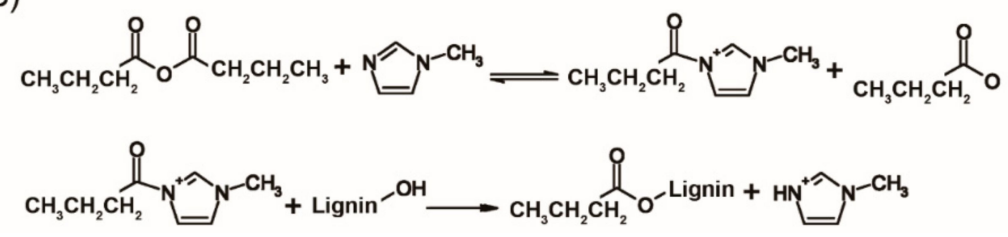

Figure 4. The chemical reaction mechanisms of (a) direct esterification, (b) acetylation, and (c) butyration of lignin. (a) Reproduced with permission from [109], copyright 2019 Royal Society of Chemistry. (b) Reproduced with permission from [110], copyright 2016 American Chemical Society. (c) Reproduced with permission from [93], copyright 2005 American Chemical Society.

Partially acetylated lignin was isolated by aqueous acetic acid pulping [92]. Ligninbased carbon fibers were melt-spun from organosolv lignin, which was obtained from aqueous acetic acid pulping without further modification. The isolated lignin could be successfully spun into fibers due to the narrow PDI and partial acetylation of the hydroxyl groups in lignin during the pulping process. The key was that acetylation (Figure $4 \mathrm{~b}$ ) would remove hydroxyl groups and crosslinks that resist flow during the melt spinning process, rendering lignin a more flexible polymer. The spinnability improved with an increasing degree of acetylation. However, the mechanical performance of the converted carbon fibers was not very satisfactory, which was $355 \mathrm{MPa}$ for TS and 39.1 GPa for TM with a fiber diameter of $14 \mu \mathrm{m}$. The low mechanical performance was due to the rough and porous fiber structure since the melt spinning of partially acetylated lignin at high temperature $\left(>300^{\circ} \mathrm{C}\right)$ could have resulted in partial decomposition or degradation of the products. Nevertheless, this partially acetylated lignin from acetic acid pulping had the potential for generating activated carbon fibers by melt spinning [92].

Most recently, lignin-based acrylate polymers were achieved via a two-step functionalization of lignin bio-oil followed by radical polymerization [99]. The orientable new polymer was melt-spun and converted into carbon fibers with an average TS of $\sim 1.70 \mathrm{GPa}$ and TM of $~ 182 \mathrm{GPa}$. This is the melt-spun lignin-based carbon fiber with the best physical 
properties reported up to date due to its high degree of graphitization and low number of structural defects.

It is remarkably challenging to produce melt-spun lignin-based carbon fibers with satisfactory mechanical performance for composites applications (i.e., at least TS $=2 \mathrm{GPa}$ and $\mathrm{TM}=200 \mathrm{GPa}$ are required for PAN-based carbon fibers) [111]. The key technical difficulty lies in that it is hard for lignin fiber precursors to possess good chemical stability for spinnability in fiber spinning but low or adequate chemical reactivity to internally crosslink and yet not stick to each other during the stabilization process [36]. In addition, it is contradictory to allow lignin have $T_{g}$ that is low enough to ease the melt spinning process but high enough to shorten the stabilization time [88].

\section{Melt-Spun Lignin/Polymer Blend Carbon Fibers}

Apart from structural modification of lignin, blending lignin with polymers (i.e., PP, poly(vinyl alcohol) (PVA), PAN, polylactic acid (PLA), PEO, etc.) is an effective and lowcost method to improve the spinnability of lignin-based carbon fibers. Several factors that may influence the physical properties of fibers from lignin/polymer blends should be noted: source and properties of lignin, weight fraction and inherent properties of polymer, and the interactions between lignin and polymer.

An earlier example of a lignin/polymer mixture for fiber melt spinning is the lignin/ PEO system [82] with strong hydrogen bonding. The addition of PEO improved the moldability and flexibility of lignin, as well as fiber spinnability. The best mechanical properties were obtained by lignin/PEO $(97 / 3, w / w)$ carbon fibers with TS $=0.55 \mathrm{GPa}$ and $\mathrm{TM}=60 \mathrm{GPa}$. However, with greater than $5 \mathrm{wt} . \%$ PEO, the lignin/PEO fiber was thermally unstable and fused together during carbonization. Kubo et al. [33] produced melt-spun carbon fibers from hardwood lignin blended with two recyclable polymers, PET and PP. The miscibility of lignin/PET blend was good due to the strong hydrogen bonding [112]; thus, the lignin/PET carbon fibers had a smooth surface and good mechanical properties ( $\mathrm{TS}=0.7 \mathrm{GPa}$, TM = 94 GPa). However, the lignin/PP blends were not miscible, which often resulted in phase separation (Figure 5a), porous carbon fiber structure (Figure $5 b$ ), and inferior mechanical properties $(\mathrm{TS}=0.4 \mathrm{GPa}, \mathrm{TM}=54 \mathrm{GPa}$ ).

Another polymer of interest for melt spinning with lignin is PLA. Chemically modified lignin from butyration (Figure 4c) was mixed with PLA to fabricate bio-renewable and low-cost carbon fibers [83]. The precursor fibers showed enhanced melt spinnability but poor mechanical properties. Lignin loading was varied at $0 \%, 50 \%, 75 \%$, and $90 \%$ to PLA polymer. The TS of precursor fibers significantly decreased from $34 \mathrm{MPa}$ of neat PLA to less than $5 \mathrm{MPa}$ of $90 \%$ lignin/PLA fiber, and the Young's modulus decreased from $26 \mathrm{GPa}$ to $16 \mathrm{GPa}$. The inferiority of melt-spun composite fibers was mainly caused by poor compatibility or phase separation between modified lignin and PLA polymer (Figure 5c) [101]. Unfortunately, the mechanical performance of converted carbon fibers was not reported. Later, Wang et al. [80] reported lignin/PLA-based carbon fibers having an optimal TS $=0.25 \mathrm{GPa}$ and $\mathrm{TM}=11.6 \mathrm{GPa}$ (lignin/PLA mass ratio of $80 / 20$ ) by melt spinning (Figure 6a). It was believed that the interaction between lignin and PLA was responsible for the increased modulus of the blend-based carbon fibers relative to that from pure lignin $(1.7 \mathrm{GPa})$. The orientation of lignin chains along the fiber axis was low and the interaction between lignin clusters was fairly weak, corresponding to a low TM (1.7 GPa) of these lignin-based carbon fibers. When PLA was blended with lignin during the melting process, hydrogen bonds were formed between the chains of PLA and lignin. In the blends, PLA chains were oriented along the fiber axis due to its linear structure in the fiber spinning process. The oriented PLA chains promoted lignin alignment along the fiber axis with the aid of formed hydrogen bonding between the two materials (Figure 6b), leading to an improved orientation of lignin phase and an increased TM of carbon fibers. However, the volatilization of PLA during thermal stabilization and carbonization caused voids on the surface and cross-section of the fibers, thereby deteriorating the TS of the lignin/PLA carbon fibers. Other blending polymers such as PET [102] and thermoplastic 
polyurethane (TPU) [94] have been also blended with fractionated or chemically modified lignin to fabricate lignin-based carbon fibers, whose properties are shown in Table 1.
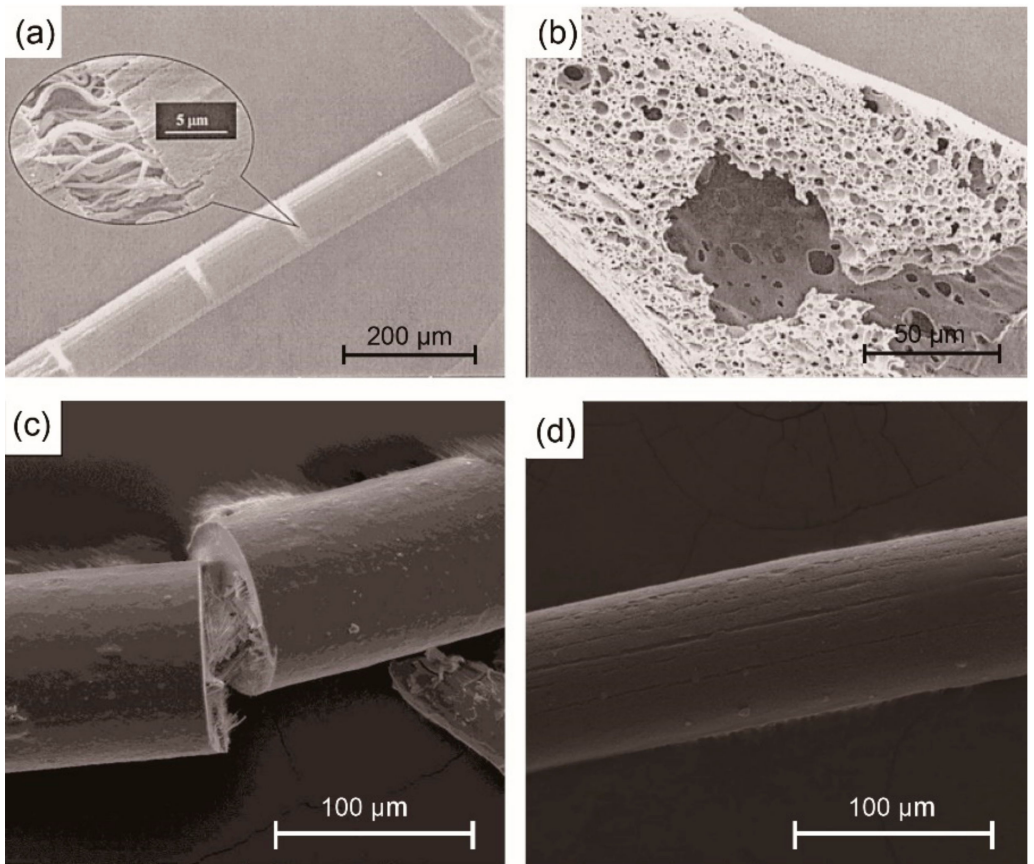

Figure 5. Scanning electron microscopic (SEM) images of melt-spun lignin/PP (w/w 75/25) fibers: (a) as-spun fibers after stretching to produce fractures along the fiber axis and (b) thermally treated fibers after being cut at a $30^{\circ}$ angle with respect to the fiber axis; (c) butyrated lignin/PLA fiber $(w / w 75 / 25)$ and (d) corresponding lignin/PLA carbon fiber by melt spinning. (a,b) Reproduced with permission from [113], copyright 2002 John Wiley and Sons. (c,d) From [101], an open-access thesis.

(a)

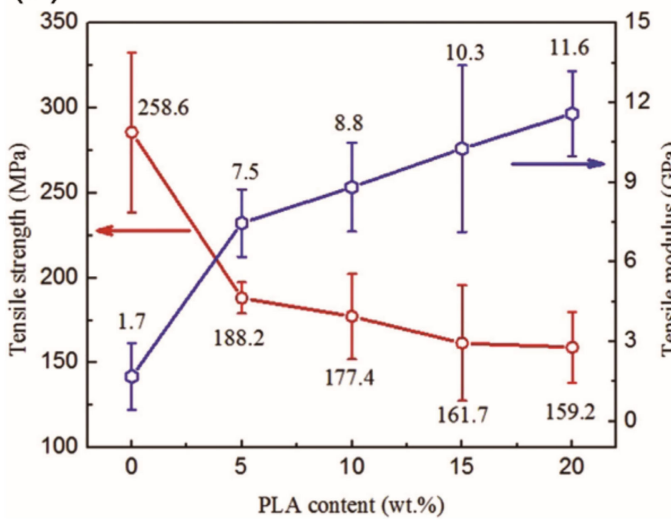

(b)

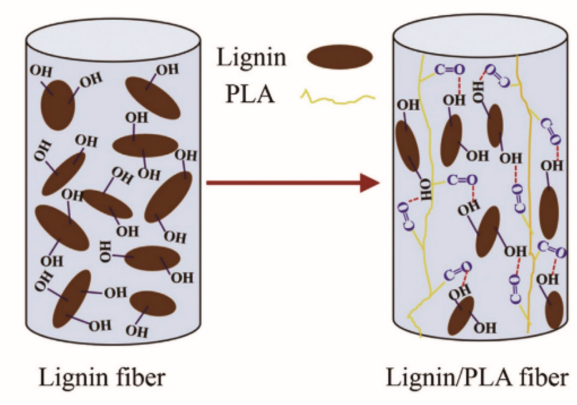

Figure 6. (a) Tensile strength and tensile modulus as a function of PLA contents for lignin/PLAbased carbon fibers and (b) schematic diagram of the orientation of lignin and lignin/PLA fibers. $(\mathbf{a}, \mathbf{b})$ Reproduced with permission from [80], copyright 2015 Elsevier.

Furthermore, different sources or types of lignin have been blended, for example, by plasticizing an infusible lignin with a fusible lignin, to enhance melt spinnability and prevent the miscibility problem in lignin/synthetic polymer blends. For instance, carbon fibers could be melt-spun from softwood Kraft lignin, which was originally infusible and later plasticized with fractionated hardwood Kraft lignin [96]. It is reported that organosolv hardwood lignin, with a lower number of aliphatic hydroxyl groups and phenolic acids, has better spinnability and yields stronger fibers with fewer defects [95]. Switch- 
grass lignins are found to be difficult to be converted into fibers with no defects for high tensile properties. However, its higher number of G-units and more condensed structure often lead to faster stabilization [70]. Accordingly, different ratios of organosolv switchgrass and yellow poplar (organosolv hardwood) lignin blends were capable of producing melt-spun lignin-based carbon fibers with no phase separation at higher stabilization rate $\left(0.5^{\circ} \mathrm{C} / \mathrm{min}\right)$ [95]. However, the mechanical performance of the resulting carbon fibers was not satisfactory, with optimal values of TS $=0.52 \mathrm{GPa}$ and $\mathrm{TM}=38 \mathrm{GPa}$.

Carbon nanotubes (CNTs) have been incorporated into lignin to achieve melt-spun carbon fibers [114]. At low CNT concentration $(<15 \%)$, CNTs facilitated fiber spinnability by increasing heat capacity of the composite fibers, which made the fiber remain molten for longer distance along the spin-line and increased fiber stretching for finer fibers with smooth surface (Figure 7a). However, the interfacial adhesion between the non-functionalized CNTs and the lignin-based carbons was too weak (Figure $7 \mathrm{~b}$ ) to cause significant increase in mechanical performance of carbon fibers. A compatibilizer by grafting lignin chains onto the surface of CNTs (CNTs-g-L) was used to prepare lignin/CNTs-g-L fibers via melt spinning [79]. With $0.5 \%$ CNTs-g-L incorporated, the TS of lignin-based carbon fibers increased from 171.2 MPa to $289.3 \mathrm{MPa}$. The strong interactions between the CNTs-g-L and lignin increased the thermal stability of lignin but disordered the graphite structure of the carbon fibers. Due to the weaker interaction between CNTs and lignin, the contribution of the CNTs to the orientation phenomenon was less effective than that of CNTs-g-L, leading to an inferior TS (258.2 MPa) to that of lignin/CNTs-g-L-based carbon fibers with $0.5 \%$ fillers (Figure $7 \mathrm{c}, \mathrm{d}$ ). Therefore, the lignin/lignin or grafted lignin/lignin blends had enhanced melt spinnability but still low mechanical properties, probably due to the less linear structure of lignin and lack of stretching in the melt spinning process.
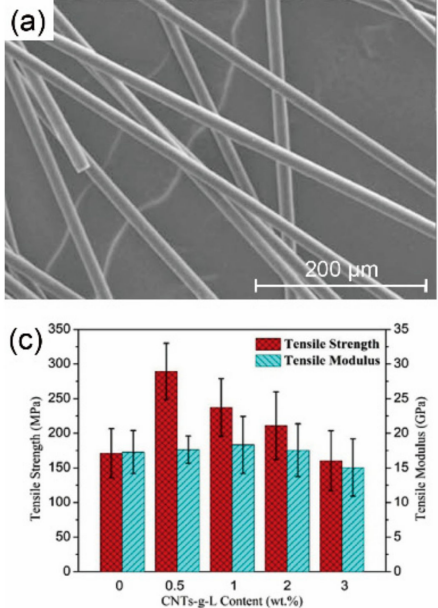

(e) Lignin/CNTs-g-L composite

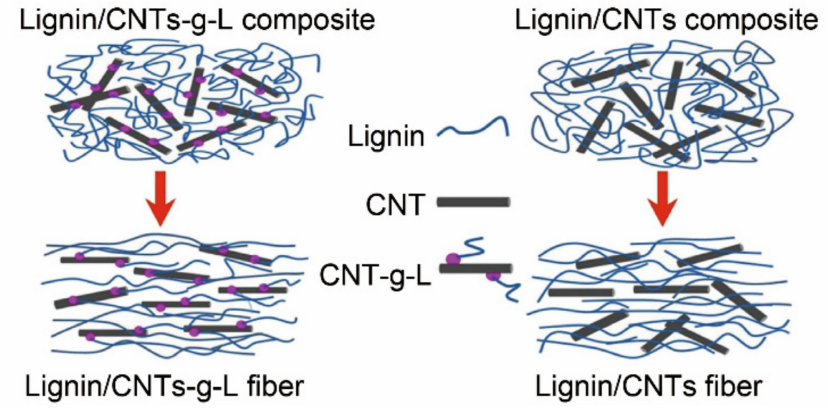

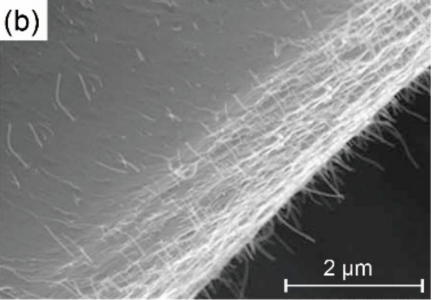

(d)

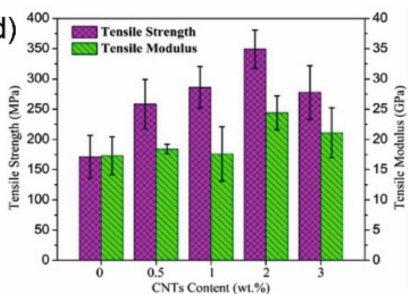

Lignin/CNTs composite

Lignin/CNTs fiber

Figure 7. SEM images of 2.5\% CNT/lignin fibers (a) before and (b) after fracture. (c) Mechanical properties of lignin/CNTs-g-L- and (d) lignin/CNT-based carbon fibers and (e) schematic diagram of the orientation of CNTs-g-L and CNTs. $(\mathbf{a}, \mathbf{b})$ Reproduced with permission from [41], copyright 2013 John Wiley and Sons. (c-e) Reproduced with permission from [79], copyright 2016 Elsevier. 
In summary, the compatibility of blending polymer with lignin is of great importance for mechanically enhancing lignin/polymer-based carbon fibers. Due to the phase separation between lignin and polymer, the porous structure resulting from the volatile fragments of polymers $[33,83,115]$, and the insufficient stretching of the fibers for chain orientation, the melt spinning technique is not the best option to produce homogenous lignin/polymer carbon fibers with good mechanical performance.

\subsubsection{Solution-Spun Lignin-Based Carbon Fibers}

Solution spinning is used to spin fibers from solutions of the dissolved polymer. It can be divided into three spinning techniques, dry spinning, wet spinning, and gel spinning, which all involve the preparation of homogenous spinning dopes. Solution-spun fibers generally have better mechanical performance than melt-spun fibers mainly due to the higher draw ratio of fibers.

As one type of the solution spinning technique, dry spinning yields fibers from polymer solutions after the evaporation of the volatile solvents [31,116]. The polymer solutions are first extruded through spinneret orifices and then into hot air for instant evaporation of the solvent. The solidified fibers or filaments may undergo further processing such as drawing before being collected onto a winder (Figure 3b). Unfortunately, the literature about dry-spun lignin-based fibers is quite limited $[27,31,32,88,116]$. This is possibly due to the higher cost and lower production efficiency of dry-spun fibers in comparison with melt-spun fibers. Moreover, dry spinning of lignin fibers may lead to voids and residual solvents within the fiber structure, which impede the fiber's mechanical performance. One benefit is that dry spinning of lignin-based carbon fibers may circumvent the fusion issue of melt-spun lignin fibers during thermal treatment for carbonization and yield fibers with enhanced performance.

The preparation of lignin-based fibers via wet spinning has been shown to be a promising way to obtain low-cost fibers [117-119]. In conventional wet spinning, the polymer solution is directly extruded into a coagulation bath. The polymeric jets are in contact with the coagulants, which are miscible with the solvent but do not dissolve the polymer. The coagulated fibers are then collected onto a take-up roller (Figure 3c), which has variable speeds to stretch the fibers [119]. A common variation of wet spinning is dry-jet or air-gap spinning, which is often used for highly viscous polymer spinning dopes [120]. In this process, the spinning dopes are first extruded into an air gap of 10-200 $\mathrm{mm}$ [121], where the polymer jets are stretched to promote better molecular orientation before entering into a liquid coagulation bath. Other processing stages are similar to those of conventional wet spinning. Due to the relatively low molecular weight of lignin, it is hard to form solution viscous enough for wet spinning. Thus, high-molecular-weight polymers, such as PVA or PAN, are often mixed with lignin to improve the spinnability of wet-spun lignin/polymer solutions. Different factors such as solution concentration (including lignin/polymer weight ratio, molecular weight, and PDI of each component, solvent type, and temperature), coagulation bath (composition and temperature), and fiber draw ratio influence the morphology, microstructure, and mechanical properties of lignin-based fibers from wet spinning.

Gel spinning is a recently developed fiber spinning technique for producing ligninbased high-performance fibers. This process is similar to wet spinning. The hot polymer solution is extruded through a spinneret into an air gap, before being placed into a cooling coagulation bath to form as-spun gel filaments. The resulting as-spun gel fibers are collected onto a rotating winder and later immersed in the coagulation bath for a certain duration of time. The fibers then pass through the air oven or hot oil, where they are heated and stretched to form high-performance solid fibers (Figure 3d). Typically, gel-spun fibers have higher draw ratios than fibers processed by other fiber spinning techniques. This is because the lower chain entanglements and remaining solvents in the gel structure promote chain stretching in the drawing process [122]. Lignin is mainly blended with PAN or PVA, which are common polymers used in gel-spun fibers [123-126]. 
Several factors that influence the mechanical performance of gel-spun lignin-based fibers should be taken into consideration. For instance, polymer molecular weight [122], polymer concentration [127], and solvent removal $[127,128]$ may affect fiber spinnability and fiber microstructure. Other factors such as the coagulation temperature, spinning dopes, coagulation solvent compositions, and fiber gelation time also impact the strength of gel-spun fibers [129]. Table 2 concisely summarizes the experimental conditions (materials, spinning parameters, thermal treatment) and key properties (fiber diameter and mechanical properties) of solution-spun lignin-based carbon fibers from the reported literature. Below, a more detailed account of the fabrication methodologies of these lignin-based carbon fibers is presented.

\section{Structurally Modified Solution-Spun Lignin-Based Carbon Fibers}

In dry spinning, lignin with low $\mathrm{T}_{\mathrm{g}}$ is not required and the surface fusion problem occurring in melt-spun lignin-based carbon fibers is avoided since no heat (but solvent) is required for fiber spinning. Otani et al. [27] described dry spinning of lignin-based carbon fiber precursor from alkali solutions. Although the obtained carbon fibers had a TS $=800 \mathrm{MPa}$, structural defects such as pores could be formed due to the residual alkali in high-temperature treatment. Zhang et al. [31,32] explored the possibility of dry spinning partially acetylated softwood lignin in acetone solution for carbon fiber precursors and discussed the effect of different factors such as spinning temperature and solution concentration on the processability and morphology of lignin-based fibers. The cross-sections of the as-spun fibers and carbon fibers (Figure $8 \mathrm{a}, \mathrm{b}$ ) showed that the fibers were slightly noncircular with surface crenulations originated from the rapid evaporation of acetone. Carbon fibers with smoother crenulations exhibited an optimal TS $=1.04 \mathrm{GPa}$ and $\mathrm{TM}=52 \mathrm{GPa}$. However, this method required a long time for thermo-oxidative stabilization to prevent the fiber fusion problem with a very low heating rate of $0.01{ }^{\circ} \mathrm{C} / \mathrm{min}$. Thus, it is not suitable for the large-scale production of low-cost carbon fibers. To increase the stabilization rate of carbon fibers, fiber precursors were further treated with UV irradiation [116]. With slightly decreased mechanical properties of carbon fibers (TS $=900 \pm 100 \mathrm{MPa}$ and $\mathrm{TM}=34 \pm 2 \mathrm{GPa}$ ), the stabilization time was significantly reduced from $40 \mathrm{~h}$ to $4 \mathrm{~h}$. Moreover, it is found that lignin purity and molecular weight play important roles in the dry spinning process of lignin-based fibers. Fractionated lignin with high purity and high number-averaged molecular weight $\left(\mathrm{M}_{\mathrm{n}}\right)$ up to $28,600 \mathrm{Da}$ had good spinnability and good thermal reactivity for rapid stabilization. The dry-spun lignin-based carbon fibers demonstrated excellent mechanical performance of TS $=1.39 \mathrm{GPa}$ and TM $=98 \mathrm{GPa}$ [88].

The enhancement of dry-spun, lignin-based carbon fiber mechanical properties includes the employment of high-purity and high-molecular-weight lignin to diminish structural defects, the chemical modification of lignin to yield a more linear architecture to facilitate molecular orientation during spinning, and the application of tension during heat treatment. In addition to lignin modification, parameters for fiber spinning and heat treatment are vital to achieve lignin-based carbon fibers with small diameter, good spinnability, and ideal mechanical performance. This may require additional efforts in optimizing the spinning process for fibers with satisfactory performance. 
Table 2. Literature summary of solution-spun lignin-based carbon fibers.

\begin{tabular}{|c|c|c|c|c|c|c|}
\hline \multirow[t]{2}{*}{ Spinning Technique } & \multirow{2}{*}{$\begin{array}{l}\text { Lignin Type/Polymer (Mass } \\
\text { Ratio)/Solvent and Reference }\end{array}$} & \multirow{2}{*}{$\begin{array}{l}\text { Modification/ } \\
\text { Coagulation Condition }\end{array}$} & \multirow{2}{*}{$\begin{array}{l}\text { Thermal Treatment } \\
\text { Stabilization/ } \\
\text { Carbonization }\end{array}$} & \multirow{2}{*}{$\begin{array}{l}\text { Diameter } \\
(\mu \mathrm{m})\end{array}$} & \multicolumn{2}{|c|}{$\begin{array}{l}\text { Maximum Mechanical } \\
\text { Properties }\end{array}$} \\
\hline & & & & & TS (GPa) & TM (GPa) \\
\hline \multirow{5}{*}{ Dry spinning } & Lignin/alkaline solution [27] & NA & $\begin{array}{l}150^{\circ} \mathrm{C}, 5^{\circ} \mathrm{C} / \mathrm{min}, 10 \mathrm{~h} \\
700^{\circ} \mathrm{C}, 10 \mathrm{~min}\end{array}$ & $20-30$ & 0.8 & $\mathrm{~N} / \mathrm{A}$ \\
\hline & $\begin{array}{l}\text { Modified softwood Kraft lignin/ } \\
\text { acetone [31] }\end{array}$ & $\begin{array}{l}\text { Acetylation with acetic } \\
\text { anhydride }\end{array}$ & $\begin{array}{l}200^{\circ} \mathrm{C}, 0.2^{\circ} \mathrm{C} / \mathrm{min} \\
1000^{\circ} \mathrm{C}, 4.5^{\circ} \mathrm{C} / \mathrm{min}\end{array}$ & $\sim 7$ & 1.04 & 52 \\
\hline & $\begin{array}{l}\text { Modified softwood Kraft lignin/ } \\
\text { acetone [116] }\end{array}$ & $\begin{array}{l}\text { Acetylation with acetic } \\
\text { anhydride }\end{array}$ & $\begin{array}{l}\text { UV treatment } 250{ }^{\circ} \mathrm{C} \text {; } \\
1000{ }^{\circ} \mathrm{C}\end{array}$ & $\mathrm{N} / \mathrm{A}$ & $0.9 \pm 0.1$ & $34 \pm 2$ \\
\hline & $\begin{array}{l}\text { Softwood Kraft lignin/acetic } \\
\text { acid-water }\left(\mathrm{H}_{2} \mathrm{O}\right)[88]\end{array}$ & NA & $\begin{array}{l}250{ }^{\circ} \mathrm{C}, 1 \mathrm{~h} ; \\
1000{ }^{\circ} \mathrm{C}\end{array}$ & $6-7$ & 1.39 & 98 \\
\hline & $\begin{array}{l}\text { Beech organosolv lignin/cellulose } \\
(30 / 70,50 / 50) /[\mathrm{DBNH}] \mathrm{OAc}[130]\end{array}$ & NA & $\begin{array}{l}\text { Stepwise: } 240,250,260,270{ }^{\circ} \mathrm{C} \text {, line speed } \\
\text { of } 15.6 \mathrm{~m} / \mathrm{h}, 23 \mathrm{~min} \text { in each stabilization } \\
\text { zone; } \\
450,600,800,1200,1500{ }^{\circ} \mathrm{C} \text {, line speed of } \\
15.6 \mathrm{~m} / \mathrm{h}, 5.5 \mathrm{~min} \text { in each carbonization } \\
\text { furnace }\end{array}$ & $4-11$ & $\sim 0.48$ & $\sim 26$ \\
\hline \multirow{4}{*}{ Wet spinning } & Hardwood lignin/DMSO [119] & $\begin{array}{l}\text { Copolymerization with AN } \\
\text { Coagulation bath: } \mathrm{H}_{2} \mathrm{O}\end{array}$ & $\begin{array}{l}280^{\circ} \mathrm{C}, 1 \mathrm{~h} ; \\
800^{\circ} \mathrm{C}, 5^{\circ} \mathrm{C} / \mathrm{min}\end{array}$ & 11 & $\mathrm{~N} / \mathrm{A}$ & $\mathrm{N} / \mathrm{A}$ \\
\hline & $\begin{array}{l}\text { Modified } \\
\text { lignosulfonate/DMSO [131] }\end{array}$ & $\begin{array}{l}\text { Esterification with acryloyl } \\
\text { chloride, then copolymerization } \\
\text { with AN (mass ratio of esterified } \\
\text { lignin/AN:30/70) } \\
\text { Coagulation bath: DMSO } / \mathrm{H}_{2} \mathrm{O}\end{array}$ & $\begin{array}{l}250{ }^{\circ} \mathrm{C}, 10^{\circ} \mathrm{C} / \mathrm{min}, 1 \mathrm{~h} ; \\
1400^{\circ} \mathrm{C}, 10^{\circ} \mathrm{C} / \mathrm{min}\end{array}$ & $10-20$ & 1.1 & $\mathrm{~N} / \mathrm{A}$ \\
\hline & $\begin{array}{l}\text { Modified } \\
\text { lignosulfonate/DMSO [132] }\end{array}$ & $\begin{array}{l}\text { Esterification with acryloyl } \\
\text { chloride, then copolymerization } \\
\text { with AN (mass ratio of esterified } \\
\text { lignin/AN: } 10 / 90,15 / 85,20 / 80 \text {, } \\
25 / 75,30 / 70) \\
\text { Coagulation bath: DMSO } / \mathrm{H}_{2} \mathrm{O} \\
(60 / 40 w / w), 60^{\circ} \mathrm{C}\end{array}$ & $\begin{array}{l}250^{\circ} \mathrm{C}, 10^{\circ} \mathrm{C} / \mathrm{min}, 1 \mathrm{~h} ; \\
1400^{\circ} \mathrm{C}, 10^{\circ} \mathrm{C} / \mathrm{min}, 10 \mathrm{~min}\end{array}$ & $19-35$ & $0.65 \pm 0.05$ & $\mathrm{~N} / \mathrm{A}$ \\
\hline & $\begin{array}{l}\text { Wheat straw lignin/PAN }(1,3.53,5 \text {, } \\
8.6,13.3 / 20) / \text { DMSO [133] }\end{array}$ & Coagulation bath: $\mathrm{H}_{2} \mathrm{O}$ & $\begin{array}{l}250^{\circ} \mathrm{C}, 1^{\circ} \mathrm{C} / \mathrm{min}, 0.5 \mathrm{~h} ; \\
1400^{\circ} \mathrm{C}, 10^{\circ} \mathrm{C} / \mathrm{min}, 20 \mathrm{~min}\end{array}$ & $20-50$ & $0.3-0.5$ & $<100$ \\
\hline
\end{tabular}


Table 2. Cont.

\begin{tabular}{|c|c|c|c|c|c|c|}
\hline \multirow[t]{2}{*}{ Spinning Technique } & \multirow{2}{*}{$\begin{array}{l}\text { Lignin Type/Polymer (Mass } \\
\text { Ratio)/Solvent and Reference }\end{array}$} & \multirow{2}{*}{$\begin{array}{l}\text { Modification/ } \\
\text { Coagulation Condition }\end{array}$} & \multirow{2}{*}{$\begin{array}{l}\text { Thermal Treatment } \\
\text { Stabilization/ } \\
\text { Carbonization }\end{array}$} & \multirow{2}{*}{$\begin{array}{l}\text { Diameter } \\
(\mu \mathrm{m})\end{array}$} & \multicolumn{2}{|c|}{$\begin{array}{l}\text { Maximum Mechanical } \\
\text { Properties }\end{array}$} \\
\hline & & & & & TS (GPa) & TM (GPa) \\
\hline & $\begin{array}{l}\text { Softwood Kraft lignin/PAN } \\
(50 / 50) / \text { DMSO [134] }\end{array}$ & $\begin{array}{l}\text { Coagulation bath: } \mathrm{DMSO} / \mathrm{H}_{2} \mathrm{O} \\
(65 / 35 \mathrm{w} / \mathrm{w}), 0.2 \mathrm{wt} . \% \text { of lignin } \\
\text { were added into coagulant bath } \\
\text { to control out-diffusion }\end{array}$ & $\begin{array}{l}300^{\circ} \mathrm{C}, 1^{\circ} \mathrm{C} / \mathrm{min}, 1 \mathrm{~h} ; \\
1200^{\circ} \mathrm{C}, 7^{\circ} \mathrm{C} / \mathrm{min}, 1 \mathrm{~h}\end{array}$ & $7.0 \pm 0.3$ & 1.2 & 130 \\
\hline & Lignin/PAN (37/20)/DMSO [135] & $\begin{array}{l}\text { Coagulation bath: DMSO } / \mathrm{H}_{2} \mathrm{O} \\
(60 / 40 w / w), 60^{\circ} \mathrm{C}\end{array}$ & $\begin{array}{l}250^{\circ} \mathrm{C}, 10^{\circ} \mathrm{C} / \mathrm{min}, 10 \mathrm{~min} \text {; } \\
\text { Stepwise: } 7000^{\circ} \mathrm{C}, 10^{\circ} \mathrm{C} / \mathrm{min}, 10 \mathrm{~min} \text {, } \\
\text { then } 1200^{\circ} \mathrm{C}, 7^{\circ} \mathrm{C} / \mathrm{min}, 30 \mathrm{~min}\end{array}$ & 13.5 & 2.1 & 224 \\
\hline & $\begin{array}{l}\text { Softwood Kraft lignin/cellulose } \\
(70 / 30) /[\text { EMIm][OAc] [136] }\end{array}$ & $\begin{array}{l}\text { Coagulation bath: } \mathrm{H}_{2} \mathrm{O} \\
5 \pm 2{ }^{\circ} \mathrm{C}\end{array}$ & $\begin{array}{l}250{ }^{\circ} \mathrm{C}, 0.2^{\circ} \mathrm{C} / \mathrm{min}, 1 \mathrm{~h} \text {; } \\
\text { Stepwise: } 600{ }^{\circ} \mathrm{C}, 1{ }^{\circ} \mathrm{C} / \mathrm{min} \text {, } \\
\text { then } 1000^{\circ} \mathrm{C}, 3{ }^{\circ} \mathrm{C} / \mathrm{min}\end{array}$ & $<10$ & 1.07 & 76 \\
\hline & $\begin{array}{l}\text { Kraft lignin/PVA/GO } \\
(66 / 29 / 5) / D M S O ~[137]\end{array}$ & Coagulation bath: isopropanol & $\begin{array}{l}300{ }^{\circ} \mathrm{C}, 2^{\circ} \mathrm{C} / \mathrm{min}, 1 \mathrm{~h} \text {; } \\
\text { Stepwise: } 500{ }^{\circ} \mathrm{C}, 2{ }^{\circ} \mathrm{C} / \mathrm{min} \text {, } \\
\text { then } 1000^{\circ} \mathrm{C}, 5^{\circ} \mathrm{C} / \mathrm{min}\end{array}$ & $\mathrm{N} / \mathrm{A}$ & 0.763 & 52 \\
\hline & $\begin{array}{l}\text { Kraft lignin/PVA } \\
(70: 30) / D M S O ~[138]\end{array}$ & Coagulation bath: 2-propanol & $\begin{array}{l}250^{\circ} \mathrm{C} ; \\
1000^{\circ} \mathrm{C}, 5{ }^{\circ} \mathrm{C} / \mathrm{min}\end{array}$ & 37 & $0.351 \pm 0.108$ & $44.5 \pm 9.6$ \\
\hline & $\begin{array}{l}\text { Softwood Kraft lignin/cellulose } \\
(70 / 30) /[\text { EMIm] [OAc] [139] }\end{array}$ & $\begin{array}{l}\text { Coagulation bath: } \mathrm{H}_{2} \mathrm{O} \\
5 \pm 2{ }^{\circ} \mathrm{C}\end{array}$ & $\begin{array}{l}\text { Stepwise: } 250{ }^{\circ} \mathrm{C}, 5^{\circ} \mathrm{C} / \mathrm{min}, 60 \mathrm{~min}, \\
600^{\circ} \mathrm{C}, 1{ }^{\circ} \mathrm{C} / \mathrm{min} \text {; } \\
800,1000,1200,1400,1600^{\circ} \mathrm{C}, 3^{\circ} \mathrm{C} / \mathrm{min}\end{array}$ & $\mathrm{N} / \mathrm{A}$ & $\begin{array}{l}1.1 \\
(\text { Carbonization } \\
\left.\text { at } 1000^{\circ} \mathrm{C}\right)\end{array}$ & $\begin{array}{l}77 \\
(\text { Carboniza- } \\
\text { tion at } \\
\left.1600^{\circ} \mathrm{C}\right)\end{array}$ \\
\hline & $\begin{array}{l}\text { Softwood Kraft lignin/cellulose } \\
(70 / 30) /[\text { EMIm] [OAc] [140] }\end{array}$ & Coagulation bath: $\mathrm{H}_{2} \mathrm{O}, 15^{\circ} \mathrm{C}$ & $\begin{array}{l}\text { Stepwise: } 200^{\circ} \mathrm{C}, 0.2^{\circ} \mathrm{C} / \mathrm{min}, 250^{\circ} \mathrm{C} \text {, } \\
1^{\circ} \mathrm{C} / \mathrm{min} \text {; } \\
\text { Stepwise: } 600^{\circ} \mathrm{C}, 1^{\circ} \mathrm{C} / \mathrm{min}, 1000^{\circ} \mathrm{C} \text {, } \\
3^{\circ} \mathrm{C} / \mathrm{min}\end{array}$ & $14-15$ & 0.88 & 67 \\
\hline & $\begin{array}{l}\text { Softwood kraft lignin/cellulose } \\
(70 / 30) /[\text { EMIm] [OAc] [136] }\end{array}$ & $\begin{array}{l}\text { Coagulation bath: } \mathrm{H}_{2} \mathrm{O} \\
5 \pm 2{ }^{\circ} \mathrm{C}\end{array}$ & $\begin{array}{l}\text { Stepwise: } 200^{\circ} \mathrm{C}, 0.2^{\circ} \mathrm{C} / \mathrm{min}, 250^{\circ} \mathrm{C}, 1 \text {, } \\
5^{\circ} \mathrm{C} / \mathrm{min}, 1,5,10 \mathrm{~h} \text {; } \\
\text { Stepwise: } 600^{\circ} \mathrm{C}, 1^{\circ} \mathrm{C} / \mathrm{min}, 1000^{\circ} \mathrm{C} \text {, } \\
3^{\circ} \mathrm{C} / \mathrm{min}\end{array}$ & $6-8$ & 1.07 & 76 \\
\hline
\end{tabular}


Table 2. Cont.

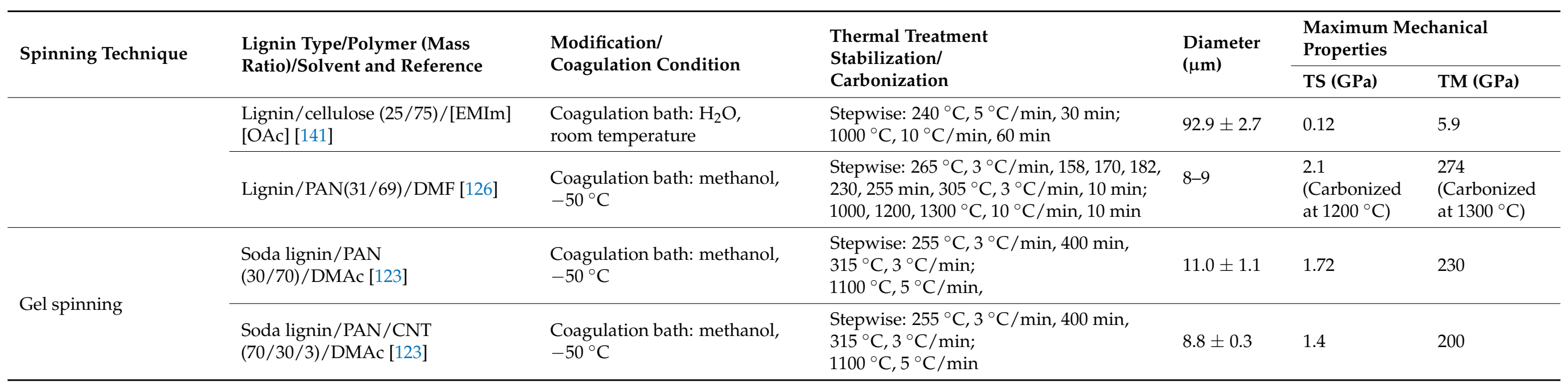

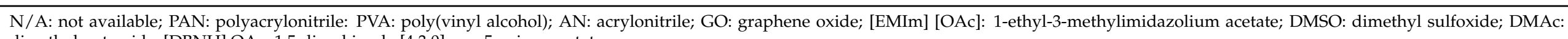
dimethylacetamide; [DBNH] OAc: 1,5-diazabicyclo [4.3.0] non-5-enium acetate. 

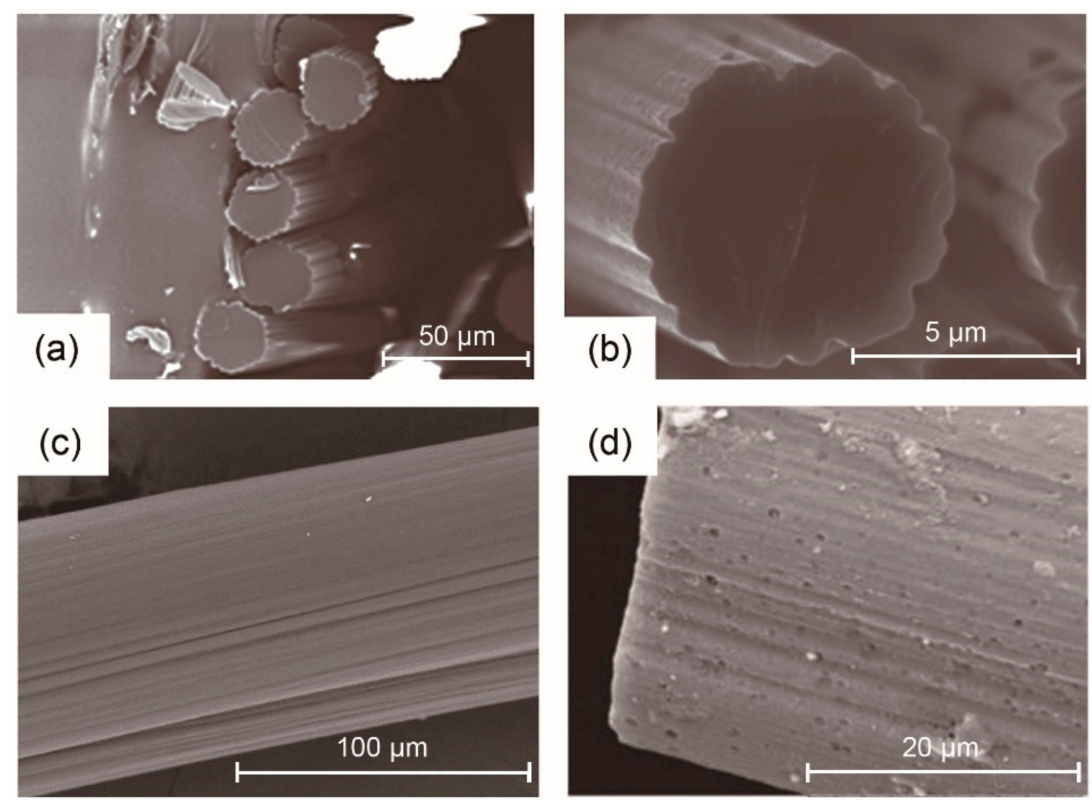

Figure 8. SEM images of (a) acetylated softwood Kraft lignin as-spun fibers and (b) corresponding carbon fibers by dry-spinning; (c) lignin/PVA (70/30) fiber and (d) corresponding lignin/PVA porous carbon fiber by wet spinning. (a,b) Reproduced with permission from [31], copyright 2014 Elsevier. (c,d) Reproduced with permission from [138], copyright 2019 John Wiley and Sons.

Lignin's relatively low molecular weight and amorphous structure render it difficult to be converted into fibers by wet spinning or gel spinning since these spinning techniques prefer high-molecular-weight raw materials with long, linear structure and adequate extensional viscosity. On the basis of this principle, there have been attempts to develop modified lignin-based wet-spun carbon fiber precursors via copolymerization or grafting. Maradur et al. [119] copolymerized hardwood lignin and acrylonitrile (AN) via a two-step radical polymerization process. The copolymer was successfully wet-spun and converted to carbon fibers with no visible voids in the fiber cross-section. Similarly, butyrated softwood Kraft lignin and organosolv lignin were used to copolymerize with PAN and further wet-spun into precursor fibers [142]. However, neither research mentioned the mechanical properties of the obtained carbon fibers. Alternatively, lignosulfonate-AN copolymer was successfully prepared via a designed two-step process consisting of esterification and free-radical copolymerization [131]. The wet-spun precursor fibers had dense structure with no voids or defects, which yielded carbon fibers with an average TS of $\sim 540 \mathrm{MPa}$. Similar work was performed to fabricate wet-spun carbon fiber precursors from copolymerized lignosulfonate-AN of different molecular weights [132]. The resulting carbon fiber possessed large diameters (19-35 $\mu \mathrm{m})$ and an average strength of $\sim 650 \mathrm{MPa}$.

Chemical modification of lignin by copolymerization greatly enhances the spinnability of the solvent-based solution due to the good dispersion of raw materials in solvent, as well as the higher molecular weight and more linear structures of the copolymers. However, the optimization of processing parameters during spinning, stabilization, and carbonization (i.e., spinning temperature, as-spun draw ratios, fiber draw ratios, heating rate, etc.) of wetspun modified lignin-based carbon fiber precursors have not been fully investigated. Thus, the advantage of a more linear structure of copolymer has not been not thoroughly exploited to obtain structurally more oriented and finer fibers with better mechanical performance.

\section{Solution-Spun Lignin/Polymer Carbon Fibers}

More recently, there has been a growing interest in preparing carbon fibers from lignin/PAN blends by solution spinning. Lignin/PAN blends combine unique properties from both polymers such as good spinnability of PAN, high char yield, and bio-renewability of lignin. Specifically, lignin's polydispersity often causes poor spinnability [29]. This is 
overcome by blending with PAN polymer, which has a linear long polymer chain, higher molecular weight, and narrower PDI. Continuous carbon fiber precursors from lignin/PAN blends by conventional wet spinning [143] were converted into carbon fibers with a TS of $\sim 2.24 \mathrm{GPa}$ and TM of $\sim 217 \mathrm{GPa}$ [133]. However, when lignin contents were above $20 \%$, voids occurred and the mechanical performance deteriorated [144]. Hollow wet-spun lignin/PAN fibers are formed due to the incorporation of lignin altering the diffusion rate $[145,146]$ and causing phase separation between lignin and PAN [147]. To yield void-free lignin/PAN-based wet-spun fibers, it is important to understand how the processing conditions (i.e., rheological behavior, solubility, etc.) $[134,148,149]$ influence the precursor fiber properties (i.e., morphology, structure, and chemistry of the fibers) since precursor quality (spinning process, structural or morphological defects, etc.) greatly determines carbon fiber quality [37]. For instance, aqueous coagulation baths containing lower than $50 \%$ dimethylformamide (DMF) concentration could be suitable for wet spinning of low-molecular-weight lignin/PAN fibers. Lignin concentration has more impact on the orientation of wet-spun lignin/PAN fibers in comparison with spinning rate and coagulation concentration [117].

In general, wet-spun lignin/PAN-based carbon fibers have a unique disordered carbon structure due to the addition of lignin. The mechanical performance of resulting carbon fibers is affected by lignin content, orientation degree, and carbonization temperature. A wheat straw lignin was blended with a commercial textile-grade PAN polymer, and then wet-spun into a water coagulation bath for the production of carbon fibers. However, the derived carbon fiber's mechanical performance was not satisfactory with TS being only 300-500 MPa and TM being below 100 GPa [144]. The voids in the lignin/PAN blend fibers, which often occurred during wet spinning, were eliminated by adding lignin to the low-temperature $\left(-50^{\circ} \mathrm{C}\right)$ coagulation bath of $65 / 35(w / w)$ dimethyl sulfoxide/deionized water (DMSO/DI water) to counterbalance the out-diffusion of lignin. Carbon fibers from $50 / 50(w / w)$ lignin/PAN fibers had a TS $=1.2 \mathrm{GPa}$ and TM $=130 \mathrm{GPa}$ [135]. Similarly, wet-spun lignin/PAN-based fibers carbonized at $1200{ }^{\circ} \mathrm{C}$ presented a dense structure without any visible macrovoids [150]. The derived carbon fibers had TS $=2.1 \mathrm{GPa}$ and $\mathrm{TM}=224 \mathrm{GPa}$. Unfortunately, the mechanical properties of carbon fibers are primarily attributed to PAN, with little contribution from lignin, and the optimization of draw ratio of wet-spun fibers has been rarely reported.

In addition, gel spinning has also been used to fabricate lignin/PAN blended fibers [123]. The as-spun lignin/PAN $(30 / 70 \mathrm{w} / \mathrm{w})$ fibers were obtained from a low-temperature $\left(-50^{\circ} \mathrm{C}\right)$ methanol coagulation bath, stored in a methanol bath at $-50^{\circ} \mathrm{C}$ for over $12 \mathrm{~h}$, and then further drawn with a high ratio of 13 before being converted into carbon fibers. Compared with pure PAN-based carbon fibers, the lignin/PAN-based carbon fibers exhibited noticeable improvements in TS (1.72 GPa) and TM (230 GPa) with no observable voids. The incorporation of lignin has a positive influence on PAN polymer chain packing, fiber stabilization, and carbonization behavior, as well as the fiber mechanical properties. Composite fibers from lignin, polyacrylonitrile (PAN), and CNTs were successfully fabricated by gel spinning and carbonized into carbon fibers [123]. The PAN/lignin/CNT-based carbon fibers exhibited significant mechanical properties ( $\mathrm{TS}=1.4 \mathrm{GPa}, \mathrm{TM}=200 \mathrm{GPa}$ ). In comparison with PAN fiber (Figure 9a,d), the decreased tensile strength was possibly due to the lower PAN orientation (Figure $9 b, c$ ) and that PAN crystalline aggregates were disturbed by lignin and CNTs, which resulted in lower crystallinity of lignin/PAN and lignin/CNT/PAN fibers (Figure 9e,f). Furthermore, PAN-sheath and lignin/PAN-core carbon fibers were successfully fabricated using a bicomponent gel spinning technique with maximum draw ratio of 20. The carbon fibers from bicomponent precursors had maximum values of TS $=2.1 \mathrm{GPa}$ and TM $=274 \mathrm{GPa}$ [126], which were comparable to those of PAN-based carbon fibers. Similar to wet-spun fibers, the mechanical properties of gel-spun fibers are related to several processing parameters, including solvent type for dissolution, temperature of the coagulation bath [151], drawing temperature, and total drawing ratio [152]. 
Thus, it is necessary to optimize the processing condition in order to achieve fibers with the best microstructure and properties.

(a)

(a)

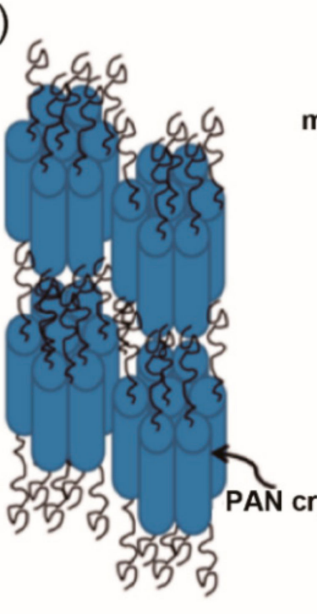

(d)

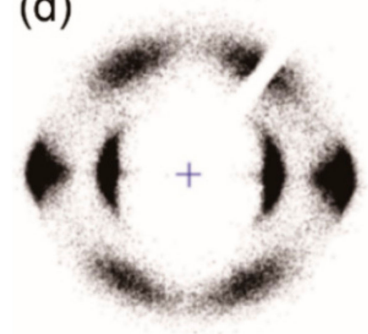

(b)

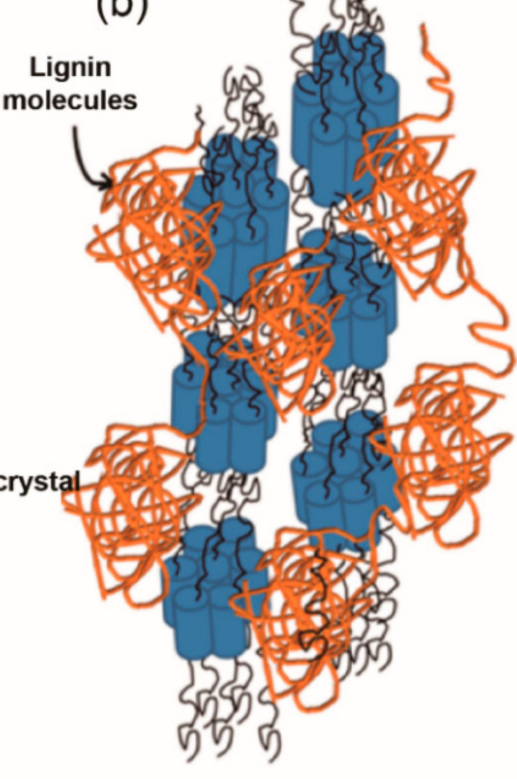

(e)

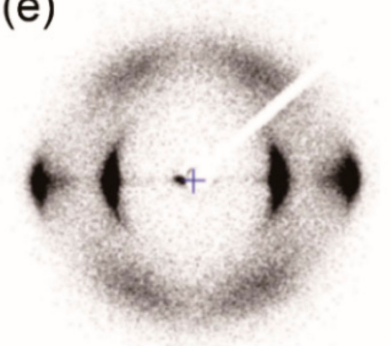

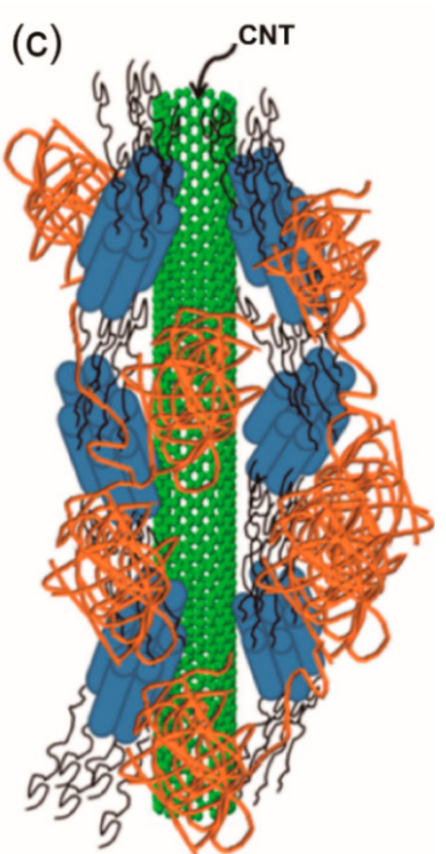

(f)

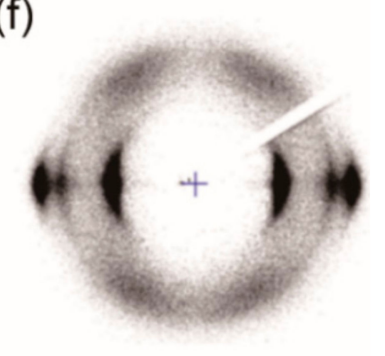

Figure 9. Schematics of gel-spun fibers of (a) PAN, (b) lignin/PAN, and (c) lignin/CNT/PAN fibers. Wide-angle X-ray diffraction (WAXD) patterns of precursor fibers (draw ratio of 13) of (d) PAN, (e) lignin/PAN, and (f) lignin/CNT/PAN fibers. (a-f) Reproduced with permission from [123], copyright 2015 American Chemical Society.

Cellulose is another common polymer blended with lignin to fabricate $100 \%$ renewable high-yield carbon fibers by solution spinning techniques. Cellulose-based precursor fiber alone often has good molecular orientation but low carbon yield (10-30\%) due to different degradation reactions which yield pyrolysis gas such as $\mathrm{CO}_{2}, \mathrm{CO}$, and other low-molar-mass carbon compounds in the carbonization process [139]. A number of stabilization and carbonization protocols $[130,136,140,153,154]$ have confirmed the feasibility of carbon fiber production from wet-spun lignin/cellulose precursor fibers. The optimal lignin/cellulose-based carbon fibers had TS $=1.07 \mathrm{GPa}$, TM $=76 \mathrm{GPa}$, diameters less than $10 \mu \mathrm{m}$, and a shorter stabilization time $(<2 \mathrm{~h})$ [153]. The effects of processing parameters (i.e., draw ratio, stabilization/carbonization temperature, lignin content, etc.) on the structure and mechanical properties of lignin/cellulose precursor fibers and carbon fibers have been investigated systematically [139,155-157], from which it is concluded that the cellulose constituent dominates precursor fiber structure and mechanical performance. Increasing lignin content decreases fiber strength due to the disturbance of oriented cellulose crystallites [141,158,159] and increases carbon yield [160] due to lignin's carbon-rich structure. However, the draw ratio of solution-spun lignin/cellulose precursor fibers seemed to have no significant influence on the carbon fiber's physical properties [155], although the detailed reasons from the perspective of fiber structure were not revealed. 
Thus, it is of great importance to achieve precursor fibers with good properties and to optimize the carbonization and stabilization conditions to yield lignin/cellulose-based carbon fibers of good quality.

In addition to the abovementioned investigations, a preferred orientation was introduced by the incorporation of graphene oxide (GO) into lignin [137] to achieve wet-spun precursor fibers and carbon fibers with higher graphitic structure [161]. However, it was found that GO had little contribution to the reinforcement of either precursors or carbon fibers processed at high temperature due to porosity [161]. Similarly, carbon fibers wet-spun from lignin/PVA blends (Figure 8c) showed a porous structure (Figure 8d), which corresponded to poor mechanical performance [138].

In summary, solution-spun lignin/polymer carbon precursor fibers have good spinnability due to the presence of long-chain polymers in the spinning dope and high carbon yield from lignin. However, more efforts should be made in altering lignin structure in order to enhance lignin orientation along precursor fibers to achieve better mechanical performance. Moreover, structure-property relationships should be emphasized systemically in the investigation of fiber solution spinning, stabilization, and carbonization processes to yield fine carbon fibers with few structural defects.

\subsubsection{Electrospun Lignin-Based Carbon Nanofibers}

Electrospinning is a well-developed and low-cost approach to fabricate continuous fibers at micrometer to nanometer scale [162-169]. With the fast evaporation of solvents, the voltage-driven polymer solution jet is formed, solidified, and collected by the grounded collector (Figure 3e). Lignin-based carbon nanofibers (CNFs) with diameters of $200 \mathrm{~nm}$ via electrospinning were first reported in 2007 [170]. It is generally difficult to electrospin a pure lignin solution because lignin cannot form enough chain entanglements within the solution, which often results in electrospray. The spinnability and fiber quality of lignin-based fibers are affected by factors such as solution properties (such as concentration, molecular weight, viscosity), processing parameters (including the solvent type, feeding rate, spinning distance, voltage, and temperature) [171-174], and apparatus design (i.e., coaxial spinning, rotating collector, etc.) $[175,176]$.

It is highly attractive to produce electrospun fibers with good mechanical performance by tailoring the fiber structure at multiscale (from nanoscale to microscale) [177]. The main limitations of electrospun lignin-based fibers are low yield, low strength, and fiber fusion during the spinning process. Moreover, it is quite difficult to measure the mechanical properties of electrospun single nanofiber since extremely tiny loads for fiber deformation, as well as careful handling of the nanofibers, are required. Alternatively, limited data has been reported on the mechanical properties of electrospun lignin-based nanofiber films or mats, which are obtained either by physical blending of lignin with other polymers or by chemical modification $[170,178,179]$ of lignin for different applications, especially for nanoscale carbon fibers in energy fields [180].

\section{Structurally Modified Electrospun Lignin-Based Carbon Nanofibers}

Different modifications have been applied to lignin for better electrospinnability. Electrospun submicron platinum $(\mathrm{Pt})$-doped lignin-based CNFs were prepared $[164,181]$. Phosphorus-functionalized lignin-based electrospun fibers were converted into CNFs with diameter of 400-1000 $\mathrm{nm}$ and mechanical performance (TS $=303 \mathrm{MPa}$ and TM = 4 GPa) [182] comparable to that of melt-spun lignin-based fibers. Fractionated lignin was dissolved in different solvent systems (i.e., dimethylacetamide (DMAc), DMF, etc.) to investigate the optimum condition for mass production of needless electrospun lignin-based CNFs potentially for the electronics industry [183]. You et al. [184] produced organosolv lignin CNFs by reacting with hexamine to crosslink fibers in the stabilization process. The produced CNFs had structural integrity and high specific surface area, as well as a significant percentage of mesopores. Schlee et al. [185] obtained $\mathrm{CO}_{2}$-activated Kraft lignin-based CNFs without any other binder polymers or additives. The specific surface area, pores, 
and the graphitic domains of CNFs significantly increased, which contributed to the improved electrochemical performance. Due to the porous nature of lignin-based CNFs, the main application was focused on sustainable and innovative electrode materials for flexible high-performance supercapacitors [186]. Thus, the mechanical performance of these electrospun modified lignin-based CNFs has rarely been reported.

\section{Electrospun Lignin/Polymer Carbon Nanofibers}

The polymers blended with lignin to form nanosized carbon fibers by electrospinning are similar to those used in melt spinning or solution spinning. However, the mechanical performance of electrospun lignin/polymer blends-based carbon micro- and nanofibers is generally much inferior to that of conventional fibers [44].

PEO was blended with different types of lignin (ethanol/organosolv, formic acid/acetic acid lignin and Kraft lignin) at a mass ratio of 95/5 to investigate the carbonization behavior of electrospun fibers [187]. It was found that fibers with low-molecular-weight ethanol/organosolv lignin could not be stabilized as they melted, while the other two types of lignin resulted in defective carbon fibers with poor mechanical performance due to the abundant side chains in lignin structure. Kraft lignin yielded carbon fibers with a higher degree of graphitization and better mechanical properties (Table 3) due to better molecular orientation and fewer side chains. Moreover, fractionated lignin with higher molecular weight, narrower PDI, and a more linear structure effectively enhanced the mechanical properties of electrospun carbon fibers (TM $=40 \mathrm{MPa}$ and TS $=6.1 \mathrm{GPa})$ [188] Incorporation of $5 \mathrm{wt}$ \% nanocrystalline cellulose (NCC) into lignin/PEO yielded bead-free electrospun CNFs with TS of $\sim 40 \mathrm{MPa}$ and TM of $\sim 6.7 \mathrm{GPa}$ [189], although the presence of NCC had no significant influence on fiber performance.

Table 3. Performance of electrospun CNFs from unmodified lignin/polymer blends.

\begin{tabular}{|c|c|c|c|c|c|}
\hline $\begin{array}{l}\text { Lignin/Polymer } \\
\text { (Mass Ratio)/Solvent } \\
\text { and Reference }\end{array}$ & Processing Parameters & $\begin{array}{l}\text { Carbonization } \\
\text { Temperature }\left({ }^{\circ} \mathrm{C}\right)\end{array}$ & Diameter (nm) & $\begin{array}{c}\text { Tensile } \\
\text { Strength (MPa) }\end{array}$ & $\begin{array}{c}\text { Young's } \\
\text { Modulus (GPa) }\end{array}$ \\
\hline $\begin{array}{l}\text { Lignin/PEO } \\
(95 / 5) / D M F[188]\end{array}$ & $\begin{array}{l}\text { Voltage: } 20 \mathrm{kV} \\
\text { Flow rate: } 0.8 \mathrm{~mL} / \mathrm{h}\end{array}$ & 1000 & $867 \pm 212$ & $40 \pm 3$ & $6.1 \pm 0.3$ \\
\hline $\begin{array}{l}\text { Lignin/PEO } \\
(95 / 5) / D M F ~[187]\end{array}$ & $\begin{array}{l}\text { Voltage: } 20 \mathrm{kV} \\
\text { Flow rate: } 0.5 \mathrm{~mL} / \mathrm{h} \\
\text { Distance: } 20 \mathrm{~cm}\end{array}$ & 1000 & $1007 \pm 70$ & $15.58 \pm 2.10$ & $24.54 \pm 3.29$ \\
\hline $\begin{array}{l}\text { Lignin/PEO } \\
(28 / 0.2) / D M F[190]\end{array}$ & $\begin{array}{l}\text { Voltage: } 15 \mathrm{kV} \\
\text { Flow rate: } 0.02 \mathrm{~mL} / \mathrm{min}\end{array}$ & 1000 & $634 \pm 87$ & $32 \pm 9$ & $4.8 \pm 0.6$ \\
\hline $\begin{array}{l}\text { Lignin/PEO (95/5- } \\
\text { 99.9/0.1)/DMF [191] }\end{array}$ & Flow rate: $0.42 \mu \mathrm{L} / \mathrm{s}$ & 1000 & $465 \pm 76$ & $11.64 \pm 6.94$ & $2.37 \pm 0.78$ \\
\hline $\begin{array}{l}\text { Lignin/PEO } \\
(99 / 1) / D M F ~[192]\end{array}$ & $\begin{array}{l}\text { Voltage: } 20 \mathrm{kV} \\
\text { Flow rate: } 0.01 \mathrm{~mL} / \mathrm{min} \\
\text { Distance: } 25 \mathrm{~cm}\end{array}$ & $800,900,1000$ & $500 \pm 150$ & $33.7 \pm 6$ & $8.0 \pm 1.4$ \\
\hline $\begin{array}{l}\text { Lignin/PAN } \\
(50 / 50) / D M F[193]\end{array}$ & $\begin{array}{l}\text { Voltage: } 25 \mathrm{kV} \\
\text { Flow rate: } 0.8 \mathrm{~mL} / \mathrm{h} \\
\text { Distance: } 20 \mathrm{~cm}\end{array}$ & 1000 & $190 \pm 18$ & $21.21 \pm 3$ & $4.64 \pm 0.1$ \\
\hline $\begin{array}{l}\text { Lignin/PAN } \\
(50 / 50) / D M F[169]\end{array}$ & $\begin{array}{l}\text { Voltage: } 15 \mathrm{kV} \\
\text { Flow rate: } 5 \mu \mathrm{L} / \mathrm{min} \\
\text { Distance: } 20 \mathrm{~cm}\end{array}$ & 1000 & $1920 \pm 150$ & $22 \pm 1$ & $2.4 \pm 0.2$ \\
\hline $\begin{array}{l}\text { Lignin/PAN } \\
(50 / 50) / D M F[194]\end{array}$ & $\begin{array}{l}\text { Voltage: } 20 \mathrm{kV} \\
\text { Flow rate: } 1.0 \mathrm{~mL} / \mathrm{h} \\
\text { Distance: } 20 \mathrm{~cm}\end{array}$ & 1400 & $\mathrm{~N} / \mathrm{A}$ & $56 \pm 2$ & $3.2 \pm 0.4$ \\
\hline $\begin{array}{l}\text { Lignin/PAN } \\
(0.25 / 1) / D M F ~[195]\end{array}$ & $\mathrm{N} / \mathrm{A}$ & 1000 & 208 & $142 \pm 8$ & $10.0 \pm 0.4$ \\
\hline
\end{tabular}


PAN is the most commonly used polymer for the fabrication of lignin/polymer blend-based electrospun CNFs [196] due to its good spinnability, high molecular weight, and potential to yield high-strength carbon fibers. Butyrated lignin was used as a plasticizer to promote the thermal mobility of electrospun lignin/PAN carbon fibers in a hightemperature treatment process [169]. The butyrated lignin has lower $\mathrm{T}_{\mathrm{g}}$ since the hydroxyl groups are converted into butyl esters (Figure $4 \mathrm{c}$ ). The inter-fiber bonding resulted in modified lignin/PAN-based carbon fibers with enhanced mechanical performance $(\mathrm{TS}=83 \mathrm{MPa}$, $\mathrm{TM}=6.1 \mathrm{GPa}$ ) compared to unmodified ones (Table 3, $\mathrm{TS}=22 \mathrm{MPa}, \mathrm{TM}=2.1 \mathrm{GPa}$ ). Lignins from different extraction processes had various structures, which affected the mechanical performance of CNFs [195]. CNFs from soda lignin/PAN had fewer defects and higher mechanical properties (TM $=142 \mathrm{MPa}$, TS $=10 \mathrm{GPa}$ ) than Kraft lignin/PAN-based CNFs (TS = 99 MPa, TM = 8.6 GPa) due to the more linear structure of soda lignin. Furthermore, fractionated lignin/PAN CNFs had a modulus (21.8 GPa) comparable to commercially available carbon fibers (10-25 GPa) [30].

Iodine treatment was employed before the stabilization of lignin/PAN nanofibers to form charge transfer complexes with aromatic rings [194]. This allowed a higher heating rate $\left(2{ }^{\circ} \mathrm{C} / \mathrm{min}\right)$ to be used and facilitated the formation of $\mathrm{CNFs}$ with fewer defects, higher graphitization degree, and good mechanical performance (TS $=89 \mathrm{MPa}, \mathrm{TS}=5.3 \mathrm{GPa}$ ). Dai et al. [197] added graphene into lignin/PAN-based CNFs to enhance the Young's modulus (2.82 GPa), increase the degree of graphitization, and lower the hydrophobicity. Modified lignin was also blended with PAN to improve its properties. Lignin-grafted-PAN copolymer alone yielded CNFs with a TS of $\sim 89.4 \mathrm{MPa}$ [163], and it was also used as a compatibilizer between lignin and PAN to increase the specific tensile strength of the CNFs to $\sim 160 \mathrm{GPa} \cdot \mathrm{mm}^{3} / \mathrm{g}$ and the Young's modulus to $\sim 14,000 \mathrm{GPa} \cdot \mathrm{mm}^{3} / \mathrm{g}$ [198]. The spinnability of catalytic depolymerized lignin bio-oil/PAN solution by electrospinning has also been investigated [199]. The small-molecule lignin bio-oil with high reactivity and low heterogeneity facilitated molecule orientation. The best electrospun CNFs were obtained by blending a solution ratio of $80 \mathrm{wt} . \%$ lignin and $20 \mathrm{wt} . \%$ PAN, with TS $=32.76 \mathrm{MPa}$ and $\mathrm{TM}=4.78 \mathrm{GPa}$.

PVA has also been also blended with lignin to prepare electrospun CNFs. However, the oxygen-rich structure of PVA often results in low carbon yield ( $<10 \mathrm{wt} . \%)$ and microporosity [200] in the high-temperature treatment process. A twisted lignin/PVA CNFs-based yarn was fabricated after electrospinning with rotating motor assembly to introduce a gradual increase in mechanical properties due to the elimination of fiber voids and decreased porosity [201]. The highly twisted fibers exhibited TS $=526.3 \mathrm{MPa}$, which was much higher than that of the untwisted ones (TS $=48.5 \mathrm{MPa}$ ). Although a lot of work has been reported on the electrospinning of lignin/PVA CNFs, most studies focused on other performance, such as electrochemical performance instead of mechanical properties.

Apart from PEO, PAN, and PVA, other polymers such as cellulose acetate [202], cellulose [203], polyvinylpyrrolidone (PVP) [204], poly(methyl methacrylate) (PMMA) [205], and PET [162] have been blended with lignin to yield electrospun CNFs for different applications. However, the mechanical performance was hardly reported.

\subsubsection{Centrifugal-Spun Lignin-Based Carbon Fibers}

Centrifugal spinning is a simple and controllable technique for the fabrication of nanofibers by subjecting the spinning solution to a centrifugal force (Figure 3f), which is different from the electric force of electrospinning. This fiber spinning technique is denoted as rotary jet spinning [206] or force-spinning [207], which can possibly yield lignin-based nanofibers. Different factors, such as fluid viscosity, collecting distance, rotation speed, and structure of spinneret, affect the fiber diameter, morphology, and mechanical properties. Although centrifugal spinning can achieve high fiber productivity, the preparation of carbon nanofibers with lignin is still in its infancy. Recently, the spinning parameters of lignin-based nanofibers via centrifugal spinning from lignin/thermoplastic polyurethane 
polymer blends were optimized to obtain thermally stable nanofibers with diameters below $500 \mathrm{~nm}$ [208]. However, more investigations need to be conducted.

\subsection{Lignin as Fiber Reinforcement}

Traditionally, one- (1D) and two-dimensional (2D) fillers are used to reinforce polymeric materials. 1D fillers, like carbon nanotubes (CNTs), are popular due to their inherent high strength (50-150 GPa) and high modulus (1 TPa) $[209,210]$. Graphene sheets are 2D fillers with superior mechanical properties (ultimate TS of $\sim 130 \mathrm{GPa}$ and TM of $\sim 1 \mathrm{TPa}$ ) [211].The possibility of utilizing 3D lignin as a filler for the reinforcement of the polymer in the forms of films [212-214], hydrogels [215], fibers [216], etc. for different applications provides a unique understanding of polymer reinforcement. This section summarizes lignin-reinforced polymeric fibers regarding their spinnability and mechanical properties.

Lignin has been investigated as a filler for biobased fibers [81]. Melt extruded lignin/PP and lignin/PE fibers show significantly reduced spinnability and mechanical properties with increasing lignin content. The same phenomenon has been observed in lignin/PAN fibers [117], which are typically obtained by wet spinning [217]. Dong et al. [118] blended lignosulfonate (LS)/PAN to prepare fibers via wet spinning. PAN and LS have good miscibility due to the sulfonyl groups in LS molecules and the adsorption of LS onto the macromolecular chains of PAN. As a result, there was no phase separation in the composite fibers. The LS/PAN $(47 / 53 w / w)$ blend fibers had low mechanical performance with TM $=0.72 \mathrm{GPa}$ and TS $=15.45 \mathrm{MPa}$. Textile-grade lignin/PAN fibers from dry-jet wet spinning developed homogeneous and smooth surfaces with a draw ratio up to 10 , fineness values of $\sim 6 \mathrm{dtex}$, TS of $\sim 616 \mathrm{MPa}$, and TM of $\sim 30 \mathrm{GPa}$ [218]. Composite fibers have lower mechanical performance than pure PAN fibers due to lignin disrupting the PAN molecular arrangement and decreasing nitrile interactions between PAN polymer chains. Studies about wet-spun lignin/PAN hollow fibers at different ratios have indicated that porosity increases firstly and then reduces as the draw ratio increases, and that it is important to use as-prepared spinning dopes with good homogeneity to increase fiber spinning stability [219].

In summary, the dramatic decrease in mechanical properties of wet-spun lignin/PAN fibers is caused by the decrease of the crystallinity and orientation. The amorphous structure of lignin may disturb or hinder the growth of crystalline domains as a function of its random distribution among PAN chains. Therefore, PAN crystallites are randomly oriented within the fiber. Moreover, fibers with higher lignin content have lower orientation, which further strengthens the hypothesis that the addition of lignin constrains the formation of a more homogeneously ordered structure. Obvious reductions in mechanical performance observed in fibers with high lignin content can be interpreted as a sign of low axial orientation of polymer chains in fiber structure.

Nevertheless, lignin has the potential to reinforce polymers since it is compatible with polar polymers due to its intrinsic polar structure [220]. Kubo et al. [221] claimed that the strong intermolecular interactions between lignin and PVA resulted in good miscibility between the two materials. The spinnability of composite fibers with short-chain and long-chain PVA by melt extrusion were investigated. Short-chain PVA had better spinnability than long-chain PVA due to the lower viscosity. However, mechanical performance was not reported to support the statement of strong interactions between lignin and PVA. Lu et al. [124] reported 5\% lignin/PVA gel-spun fiber with values of maximum $\mathrm{TS}=1.1 \mathrm{GPa}$, TM $=37 \mathrm{GPa}$, and toughness of $\sim 17 \mathrm{~J} / \mathrm{g}$, which were much higher than those of neat PVA fibers. The enhancement of fiber performance was attributed to intermolecular bonding between lignin and PVA, a high index of crystallinity, and mild alignment of lignin upon fiber spinning. Intermolecular hydrogen bonding between PVA and lignin enabled better alignment of lignin's molecular groups as PVA polymer chains were highly stretched along the fiber axis during drawing. However, fibers with higher lignin content had lower mechanical properties due to the voids, lignin aggregation, and poor chain 
alignment in the fiber structure. To further improve the mechanical properties and molecular anisotropy, Lu et al. [125] examined the effects of gel aging on fiber structure and properties. The $5 \%$ lignin fibers had the highest TS of $\sim 1.4 \mathrm{GPa}$ from 1-day gel aging, as well as maximum Young's modulus of $\sim 54 \mathrm{GPa}$ and toughness of $\sim 25 \mathrm{~J} / \mathrm{g}$ after 14-day aging. Water in the aging solvent, as a plasticizing agent, aided the swelling of the gel microstructure and resulted in a higher fiber draw ratio of $5 \%$ lignin fibers. Moreover, ternary systems of lignin/PVA-based gel-spun fibers with a second filler such as glucarate [222] or GO [223] were investigated. The intermolecular interaction between the polymer matrix and fillers has great impact on the microstructure and further mechanical performance of the obtained fibers.

Ma et al. [224] utilized Kraft and organosolv lignins as fillers to fabricate cellulosebased composite fibers using a dry-jet wet spinning method. It is claimed that fiber spinnability and strength highly depend on the lignin content and spinning dope concentration. The increase in dope concentration to $20 \mathrm{wt} . \%$ (if the cellulose/lignin ratio is 1:1) and low spinning temperature enhanced the spinnability. Among lignin-reinforced cellulose fibers, $10 \%$ Kraft lignin/cellulose fibers had the highest TS of $\sim 700 \mathrm{MPa}$ and TM of $\sim 24 \mathrm{GPa}$. However, higher lignin content leads to lower mechanical properties due to lower crystallinity. It is also implied that organosolv lignin is possibly a better filler than Kraft lignin due to the former having higher chemical homogeneity (sulfur-free) and thermal stability, as well as a lower tendency of fragmentation. Similarly, lignin/cellulose fibers with up to $50 \%$ lignin were achieved by dry-jet wet spinning [225]. The investigations of the fibers indicated a core/shell structure with a dense core and a porous shell at lower lignin content. It was concluded that cellulose governed fiber formation and final properties while lignin served mainly as a filler in the core region. Spinnability decreased with increasing lignin content due to the decreasing maximum draw ratio, as did the mechanical properties of fibers. Moreover, it was found that lignin increased the maximal critical draw ratio of a cellulose solution with 50\% lignin and improved the spinning stability [226]. However, other factors such as spinneret geometry and choice of coagulant remain to be investigated.

It should be noted that lignin tends to leach into the coagulation bath of solutionspun lignin-containing fibers $[124,136,225,227]$, which may affect the solid content and performance of the final fibers. Apart from selecting the appropriate coagulation solvent [124], lignin leaching was lessened by the incorporation of modified lignin into wet-spun cellulose-based fibers, which favored the production of biobased fibers with more lignin retained in fiber structure [228]. The modified lignin had fewer hydroxyl groups due to the enzymatic radical oxidation reactions of lignin with white-rot fungus Obba rivulosa increasing the content of aromatic rings connected by carbon/carbon (C-C) bonds. Moreover, spinnability of lignin/cellulose wet-spun fibers decreased as the lignin content went up. By optimizing the draw ratio of wet-spun fibers, both carbohydrate fraction and lignin moieties were highly orientated along the fiber axis, although a slight decrease in TS was observed at higher lignin content.

As for electrospun lignin-based polymeric fibers, the main focus has been the optimization of lignin/polymer nanofibers for bead-free fibers by forming intermolecular interactions between lignin and polymers, such as PEO [179], PVA [229-232], and cellulose acetate [233]. The properties (viscosity, electroconductivity, and surface tension) of the lignin/PVA dispersion with different loadings of cellulose nanocrystals (CNCs) were correlated with electrospinnability [229-231]. The intermolecular interaction of hydrogen bonding among the polymer matrix, lignin, and the dispersed CNCs plays an important role in improving the spinnability and thermomechanical properties of composite electrospun fibers. Moreover, different surfactants (anionic, cationic, and nonionic surfactants) were introduced to yield bead-free lignin/PVA nanofibers with reduced fiber size by decreasing the surface tension of spinning dopes and increasing polymer entanglements [232]. To improve the miscibility of lignin and cellulose acetate, lignin-polyester copolymers were synthesized before electrospinning [233]. It was shown that the incorporation of lignin copolymers into cellulose acetate fibers enhanced the mechanical performance of 
the material with maximum TS $=8.9 \pm 2.4 \mathrm{MPa}$ and $\mathrm{TM}=471.0 \pm 56.4 \mathrm{MPa}$ due to better alignment and higher crystallinity. These researches highlight lignin's great potential to be further used or examined as a fiber for load-bearing applications.

\section{Future Directions}

Even though lignin fibers have been manufactured by various textile spinning techniques over the last 50 years, there are still many difficulties in providing lignin-based fibers with satisfactory physical properties for industrial applications, mainly due to its amorphous structure, brittleness, and immiscible properties. To successfully fabricate ligninbased fibers, it is structurally modified or blended with polymers to improve its spinnability. Lignin-based fibers with greater strength require lignin with high purity, high molecular weight, and a narrow PDI. Even though lignin itself is fairly cheap, the preparations of lignin (i.e., extraction, modification, etc.) for fiber spinning can be quite intricate and expensive. Thus, suitable lignin-containing systems that, when processed into fibers satisfy both property requirements and cost objectives, have rarely been demonstrated. Future advances toward lignin-based high-performance fibers (Figure 10) are listed below.

1. Extraction or pretreatment resulting in lignin with different structural chemistries suitable for various fabrication techniques to manufacture lignin-based high-performance fibers should be more systematically studied to yield lignin with higher molecular weight and narrower PDI. Although efforts have been made to fabricate lignin/cellulose fibers [224-226] that resemble fibrils in plant cell walls, there is still a gap in the fundamental knowledge of the physics and chemistry of natural lignin and how it reinforces or provides strength in wood. The knowledge should be gained to potentially develop fiber biomimetics with good mechanical properties.

2. The reported lignin grafting with CNTs [79] or PAN [163], RAFT polymerization [99], and copolymerization with AN $[119,234]$ showed promising results. The future trend of lignin chemical modification should focus on increasing molecular weight and polymer linearity by grafting lignin onto different polymers or via polymerization or copolymerization of lignin with other monomers. For lignin/polymer blends, lignin modification should not be limited to the reduction of lignin's hydroxyl groups to be compatible with hydrophobic polymers such as PET and PP [234]. More studies of lignin modification should also be conducted to enhance its compatibility with polar polymers.

3. Lignin fiber spinning research is still in its infancy and requires more efforts in material and spinning technique development. Solution spinning of lignin-based fibers should be more thoroughly investigated as an alternative to traditional melt spinning [41]. Solution-spun fibers have higher molecular orientation along the fiber axis, which is vital to achieve high-strength and high-modulus lignin-based fibers. In particular, the optimization of spinning parameters (e.g., draw ratio, solvents, coagulation bath composition, and temperature) that aid the orientation of molecules should be conducted to achieve fibers with small diameter, high crystallinity, high orientation, and high mechanical properties.

With a better understanding of the role of natural lignin as a reinforcing filler, along with the progress of modification chemistry and the development of fiber spinning technology, it is becoming increasingly likely that lignin will be a promising renewable resource for the manufacture of low-cost high-performance products for applications such as carbon fibers or structure reinforcement. 


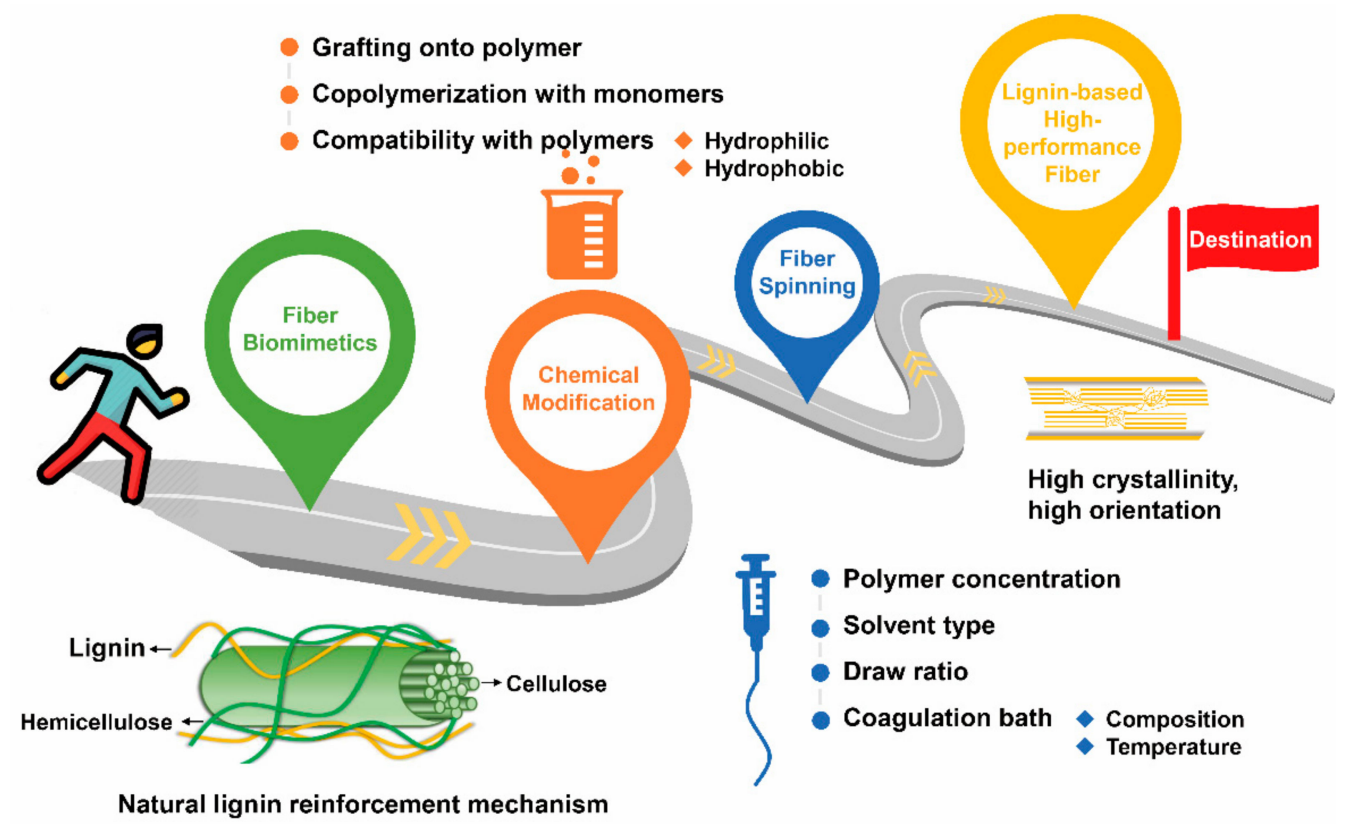

Figure 10. Roadmap of future research directions of lignin-based high-performance fibers.

Author Contributions: Conceptualization, Y.J. and C.L.; literature search, Y.J., J.L. and Y.C.; draft and revision, Y.J. and C.L. All authors have read and agreed to the published version of the manuscript.

Funding: This research was funded by the National Natural Science Foundation of China (Grant no. 51903033), the Shanghai Sailing Program, China (Grant no. 19YF1400800), and the Fundamental Research Funds for the Central Universities (Grant nos. 2232019D3-13 and 2232020G-01).

Institutional Review Board Statement: Not applicable.

Informed Consent Statement: Not applicable.

Data Availability Statement: No new data were created or analyzed in this study. Data sharing is not applicable to this article.

Conflicts of Interest: The authors declare no conflict of interest.

\section{References}

1. Fernandes, E.M.; Pires, R.A.; Mano, J.F.; Reis, R.L. Bionanocomposites from lignocellulosic resources: Properties, applications and future trends for their use in the biomedical field. Prog. Polym. Sci. 2013, 38, 1415-1441. [CrossRef]

2. Faruk, O.; Bledzki, A.K.; Fink, H.-P.; Sain, M. Biocomposites reinforced with natural fibers: 2000-2010. Prog. Polym. Sci. 2012, 37, 1552-1596. [CrossRef]

3. Pinto, M.A.; Chalivendra, V.B.; Kim, Y.K.; Lewis, A.F. Effect of surface treatment and Z-axis reinforcement on the interlaminar fracture of jute/epoxy laminated composites. Eng. Fract. Mech. 2013, 114, 104-114. [CrossRef]

4. Dobos, A.M.; Onofrei, M.-D.; Stoica, I.; Olaru, N.; Olaru, L.; Ioan, S. Rheological properties and microstructures of cellulose acetate phthalate/hydroxypropyl cellulose blends. Polym. Compos. 2012, 33, 2072-2083. [CrossRef]

5. Necula, A.M.; Olaru, N.; Olaru, L.; Homocianu, M.; Ioan, S. Influence of the Substitution Degrees on the Optical Properties of Cellulose Acetates. J. Appl. Polym. Sci. 2010, 115, 1751-1757. [CrossRef]

6. Dobos, A.M.; Stoica, I.; Olaru, N.; Olaru, L.; Ioanid, E.G.; Ioan, S. Surface properties and biocompatibility of cellulose acetates. J. Appl. Polym. Sci. 2012, 125, 2521-2528. [CrossRef]

7. Thakur, V.K.; Thakur, M.K.; Raghavan, P.; Kessler, M.R. Progress in green polymer composites from lignin for multifunctional applications: A review. ACS Sustain. Chem. Eng. 2014, 2, 1072-1092. [CrossRef]

8. Shah, D.U. Developing plant fibre composites for structural applications by optimising composite parameters: A critical review. J. Mater. Sci. 2013, 48, 6083-6107. [CrossRef]

9. Graca, M.P.F.; Rudnitskaya, A.; Faria, F.A.C.; Evtuguin, D.V.; Gomes, M.T.S.R.; Oliveira, J.A.B.P.; Costa, L.C. Electrochemical impedance study of the lignin-derived conducting polymer. Electrochim. Acta 2012, 76, 69-76. [CrossRef]

10. Rozite, L.; Varna, J.; Joffe, R.; Pupurs, A. Nonlinear behavior of PLA and lignin-based flax composites subjected to tensile loading. J. Compos. 2013, 26, 476-496. [CrossRef]

11. Laurichesse, S.; Averous, L. Chemical modification of lignins: Towards biobased polymers. Prog. Polym. Sci. 2014, 39, 1266-1290. [CrossRef] 
12. Collins, M.N.; Nechifor, M.; Tanasa, F.; Zanoaga, M.; McLoughlin, A.; Strozyk, M.A.; Culebras, M.; Teaca, C.A. Valorization of lignin in polymer and composite systems for advanced engineering applications-A review. Int. J. Biol. Macromol. 2019, 131, 828-849. [CrossRef] [PubMed]

13. Fang, W.; Yang, S.; Wang, X.L.; Yuan, T.Q.; Sun, R.C. Manufacture and application of lignin-based carbon fibers (LCFs) and lignin-based carbon nanofibers (LCNFs). Green Chem. 2017, 19, 1794-1827. [CrossRef]

14. Mao, H.; Chen, X.; Huang, R.; Chen, M.; Yang, R.; Lan, P.; Zhou, M.; Zhang, F.; Yang, Y.; Zhou, X. Fast preparation of carbon spheres from enzymatic hydrolysis lignin: Effects of hydrothermal carbonization conditions. Sci. Rep. 2018, 8, 9501. [CrossRef]

15. Thakur, V.K.; Thakur, M.K. Recent advances in green hydrogels from lignin: A review. Int. J. Biol. Macromol. 2015, 72, 834-847. [CrossRef] [PubMed]

16. Ten, E.; Vermerris, W. Recent developments in polymers derived from industrial lignin. J. Appl. Polym. Sci. 2015, 132. [CrossRef]

17. Feldman, D.; Banu, D.; Manley, R.S.J.; Zhu, H. Highly filled blends of a vinylic copolymer with plasticized lignin: Thermal and mechanical properties. J. Appl. Polym. Sci. 2003, 89, 2000-2010. [CrossRef]

18. Le Digabel, F; Avérous, L. Effects of lignin content on the properties of lignocellulose-based biocomposites. Carbohydr. Polym. 2006, 66, 537-545. [CrossRef]

19. Erakovic, S.; Veljovic, D.; Diouf, P.N.; Stevanovic, T.; Mitric, M.; Milonjic, S.; Miskovic-Stankovic, V.B. Electrophoretic deposition of biocomposite lignin/hydroxyapatite coatings on titanium. Int. J. Chem. React. Eng. 2009, 7, 113-130. [CrossRef]

20. Raschip, I.E.; Hitruc, E.G.; Vasile, C. Semi-interpenetrating polymer networks containing polysaccharides. II. Xanthan/lignin networks: A spectral and thermal characterization. High. Perform. Polym. 2011, 23, 219-229. [CrossRef]

21. Cerrutti, B.M.; de Souza, C.S.; Castellan, A.; Ruggiero, R.; Frollini, E. Carboxymethyl lignin as stabilizing agent in aqueous ceramic suspensions. Ind. Crop. Prod. 2012, 36, 108-115. [CrossRef]

22. Faria, F.A.C.; Evtuguin, D.V.; Rudnitskaya, A.; Gomes, M.T.S.R.; Oliveira, J.A.B.P.; Graca, M.P.F.; Costa, L.C. Lignin-based polyurethane doped with carbon nanotubes for sensor applications. Polym. Int. 2012, 61, 788-794. [CrossRef]

23. Wang, H.; Zou, J.; Shen, Y.; Fei, G.; Mou, J. Preparation and colloidal properties of an aqueous acetic acid lignin containing polyurethane surfactant. J. Appl. Polym. Sci. 2013, 130, 1855-1862. [CrossRef]

24. Wu, R.; Wang, X.; Li, F.; Li, H.; Wang, Y. Green composite films prepared from cellulose, starch and lignin in room-temperature ionic liquid. Bioresour. Technol. 2009, 100, 2569-2574. [CrossRef]

25. Li, Y.; Cao, X.; Qian, X.; Chen, Y.; Liu, S.Q. Immobilization of laccase in N-doped carbon hollow spheres/chitosan composite film for electrochemical detection of kraft lignin. J. Electroanal Chem 2012, 686, 7-11. [CrossRef]

26. Raschip, I.E.; Hitruc, G.E.; Vasile, C.; Popescu, M.C. Effect of the lignin type on the morphology and thermal properties of the xanthan/lignin hydrogels. Int. J. Biol. Macromol. 2013, 54, 230-237. [CrossRef]

27. Otani, S.; Fukuoka, Y.; Igarashi, B.; Sasaki, K. Method for Producing Carbonized Lignin Fiber. U.S. Patent 3,461,082, 12 August 1969.

28. Luhar, S.; Suntharalingam, T.; Navaratnam, S.; Luhar, I.; Thamboo, J.; Poologanathan, K.; Gatheeshgar, P. Sustainable and renewable bio-based natural fibres and its application for 3D printed concrete: A review. Sustainability 2020, 12, 10485. [CrossRef]

29. Li, Q.; Serem, W.K.; Dai, W.; Yue, Y.; Naik, M.T.; Xie, S.X.; Karki, P.; Liu, L.; Sue, H.J.; Liang, H.; et al. Molecular weight and uniformity define the mechanical performance of lignin-based carbon fiber. J. Mater. Chem. A 2017, 5, 12740-12746. [CrossRef]

30. Li, Q.; Xie, S.X.; Serem, W.K.; Naik, M.T.; Liu, L.; Yuan, J.S. Quality carbon fibers from fractionated lignin. Green Chem. 2017, 19, 1628-1634. [CrossRef]

31. Zhang, M.; Ogale, A.A. Carbon fibers from dry-spinning of acetylated softwood kraft lignin. Carbon 2014, 69, 626-629. [CrossRef]

32. Zhang, M.; Ogale, A.A. Effect of temperature and concentration of acetylated-lignin solutions on dry-spinning of carbon fiber precursors. J. Appl. Polym. Sci. 2016, 133. [CrossRef]

33. Kubo, S.; Kadla, J.F. Lignin-based carbon fibers: Effect of synthetic polymer blending on fiber properties. J. Polym. Environ. 2005, 13, 97-105. [CrossRef]

34. Schmack, G.; Tändler, B.; Optiz, G.; Vogel, R.; Komber, H.; Häußler, L.; Voigt, D.; Weinmann, S.; Heinemann, M.; Fritz, H.G. High-speed melt spinning of various grades of polylactides. J. Appl. Polym. Sci. 2004, 91, 800-806. [CrossRef]

35. Hufenus, R.; Yan, Y.; Dauner, M.; Kikutani, T. Melt-spun fibers for textile applications. Materials 2020, 13, 4298. [CrossRef]

36. Ogale, A.A.; Zhang, M.; Jin, J. Recent advances in carbon fibers derived from biobased precursors. J. Appl. Polym. Sci. 2016, 133. [CrossRef]

37. Huang, X. Fabrication and properties of carbon fibers. Materials 2009, 2, 2369-2403. [CrossRef]

38. Frank, E.; Steudle, L.M.; Ingildeev, D.; Sporl, J.M.; Buchmeiser, M.R. Carbon fibers: Precursor systems, processing, structure, and properties. Angew. Chem. Int. Ed. 2014, 53, 5262-5298. [CrossRef] [PubMed]

39. Souto, F.; Calado, V.; Pereira, N. Lignin-based carbon fiber: A current overview. Mater. Res. Express 2018, 5, 072001. [CrossRef]

40. Wang, S.; Bai, J.; Innocent, M.T.; Wang, Q.; Xiang, H.; Tang, J.; Zhu, M. Lignin-based carbon fibers: Formation, modification and potential applications. Green Energy Environ. 2021. [CrossRef]

41. Baker, D.A.; Rials, T.G. Recent advances in low-cost carbon fiber manufacture from lignin. J. Appl. Polym. Sci. 2013, 130, 713-728. [CrossRef]

42. Sagues, W.J.; Jain, A.; Brown, D.; Aggarwal, S.; Suarez, A.; Kollman, M.; Park, S.; Argyropoulos, D.S. Are lignin-derived carbon fibers graphitic enough? Green Chem. 2019, 21, 4253-4265. [CrossRef] 
43. Demiroğlu Mustafov, S.; Seydibeyoğlu, M.Ö. Surface Treatment of Lignin Sourced Carbon Fibers: Principles, Processes, and Challenges. In Sustainable Lignin for Carbon Fibers: Principles, Techniques, and Applications; Akpan, E.I., Adeosun, S.O., Eds.; Springer International Publishing: Cham, Swizerland, 2019; pp. 427-439.

44. Svinterikos, E.; Zuburtikudis, I.; Al-Marzouqi, M. Electrospun lignin-derived carbon micro- and nanofibers: A review on precursors, properties, and applications. ACS Sustain. Chem. Eng. 2020, 8, 13868-13893. [CrossRef]

45. Marisa, T.; Ounis, H.; Benchabane, A.; Sedira, L. Effect of lignin on the mechanical properties of a composite material based on date palm leaflets and expanded polystyrene wastes. Tecn. Ital. Ital. J. Eng. Sci. 2019, 63, 393-396.

46. Doherty, W.O.S.; Mousavioun, P.; Fellows, C.M. Value-adding to cellulosic ethanol: Lignin polymers. Ind. Crop. Prod. 2011, 33, 259-276. [CrossRef]

47. Chakar, F.S.; Ragauskas, A.J. Review of current and future softwood kraft lignin process chemistry. Ind. Crop. Prod. 2004, 20, 131-141. [CrossRef]

48. Cheng, G.; Kent, M.S.; He, L.; Varanasi, P.; Dibble, D.; Arora, R.; Deng, K.; Hong, K.; Melnichenko, Y.B.; Simmons, B.A.; et al. Effect of ionic liquid treatment on the structures of lignins in solutions: Molecular subunits released from lignin. Langmuir 2012, 28, 11850-11857. [CrossRef]

49. Qiu, X.; Kong, Q.; Zhou, M.; Yang, D. Aggregation behavior of sodium lignosulfonate in water solution. J. Phys. Chem. B 2010, 114, 15857-15861. [CrossRef]

50. Deng, Y.; Feng, X.; Zhou, M.; Qian, Y.; Yu, H.; Qiu, X. Investigation of aggregation and assembly of alkali lignin using iodine as a probe. Biomacromolecules 2011, 12, 1116-1125. [CrossRef] [PubMed]

51. Ragauskas, A.J.; Beckham, G.T.; Biddy, M.J.; Chandra, R.; Chen, F.; Davis, M.F.; Davison, B.H.; Dixon, R.A.; Gilna, P.; Keller, M.; et al. Lignin valorization: Improving lignin processing in the biorefinery. Science 2014, 344, 1246843. [CrossRef] [PubMed]

52. Kai, D.; Tan, M.J.; Chee, P.L.; Chua, Y.K.; Yap, Y.L.; Loh, X.J. Towards lignin-based functional materials in a sustainable world. Green Chem. 2016, 18, 1175-1200. [CrossRef]

53. Boerjan, W.; Ralph, J.; Baucher, M. Lignin biosynthesis. Annu. Rev. Plant Biol. 2003, 54, 519-546. [CrossRef] [PubMed]

54. Zhang, Y.; He, H.; Dong, K.; Fan, M.; Zhang, S. A DFT study on lignin dissolution in imidazolium-based ionic liquids. RSC Adv. 2017, 7, 12670-12681. [CrossRef]

55. Sen, S.; Patil, S.; Argyropoulos, D.S. Thermal properties of lignin in copolymers, blends, and composites: A review. Green Chem. 2015, 17, 4862-4887. [CrossRef]

56. Windeisen, E.; Wegener, G. Lignin as Building Unit for Polymers. In Polymer Science: A Comprehensive Reference; Matyjaszewski, K., Möller, M., Eds.; Elsevier: Amsterdam, The Netherlands, 2012; pp. 255-265.

57. Chatterjee, S.; Saito, T. Lignin-derived advanced carbon materials. ChemSusChem 2015, 8, 3941-3958. [CrossRef]

58. Mei, Q.Q.; Shen, X.J.; Liu, H.Z.; Han, B.X. Selectively transform lignin into value-added chemicals. Chin. Chem. Lett. 2019, 30, 15-24. [CrossRef]

59. Li, C.; Zhao, X.; Wang, A.; Huber, G.W.; Zhang, T. Catalytic Transformation of Lignin for the Production of Chemicals and Fuels. Chem. Rev. 2015, 115, 11559-11624. [CrossRef]

60. Karhunen, P.; Rummakko, P.; Sipila, J.; Brunow, G.; Kilpelainen, I. Dibenzodioxocins-A novel type of linkage in softwood lignins. Tetrahedron Lett. 1995, 36, 169-170. [CrossRef]

61. Choi, D.; Kil, H.S.; Lee, S. Fabrication of low-cost carbon fibers using economical precursors and advanced processing technologies. Carbon 2019, 142, 610-649. [CrossRef]

62. Irvine, G.M. The significance of the glass transition of lignin in thermomechanical pulping. Wood Sci. Technol. 1985, 19, 139-149. [CrossRef]

63. Hillis, W.E.; Rozsa, A.N. The softening temperatures of wood. Holzforschung 1978, 32, 68-73. [CrossRef]

64. Holladay, J.E.; White, J.F.; Bozell, J.J.; Johnson, D. Top Value-Added Chemicals from Biomass—Volume II-Results of Screening for Potential Candidates from Biorefinery Lignin; Pacific Northwest National Lab (PNNL): Richland, WA, USA, 2007.

65. Constantino, C.J.L.; Dhanabalan, A.; Curvelo, A.; Oliveira, O.N. Preparation and characterization of composite LB films of lignin and cadmium stearate. Thin Solid Films 1998, 327, 47-51. [CrossRef]

66. Singha, A.S.; Thakur, V.K.; Mehta, I.K.; Shama, A.; Khanna, A.J.; Rana, R.K.; Rana, A.K. Surface-modified hibiscus sabdariffa fibers: Physicochemical, thermal, and morphological properties evaluation. Int. J. Polym. Anal. Charact. 2009, 14, 695-711. [CrossRef]

67. Schutyser, W.; Renders, T.; Van den Bosch, S.; Koelewijn, S.F.; Beckham, G.T.; Sels, B.F. Chemicals from lignin: An interplay of lignocellulose fractionation, depolymerisation, and upgrading. Chem. Soc. Rev. 2018, 47, 852-908. [CrossRef] [PubMed]

68. Vishtal, A.; Kraslawski, A. Challenges in industrial applications of technical lignins. Bioresources 2011, 6, 3547-3568. [CrossRef]

69. De la Torre, M.J.; Moral, A.; Hernández, M.D.; Cabeza, E.; Tijero, A. Organosolv lignin for biofuel. Ind. Crop. Prod. 2013, 45, 58-63. [CrossRef]

70. Hosseinaei, O.; Harper, D.P.; Bozell, J.J.; Rials, T.G. Role of Physicochemical Structure of Organosolv Hardwood and Herbaceous Lignins on Carbon Fiber Performance. ACS Sustain. Chem. Eng. 2016, 4, 5785-5798. [CrossRef]

71. Shrotri, A.; Kobayashi, H.; Fukuoka, A. Catalytic Conversion of Structural Carbohydrates and Lignin to Chemicals. In Advances in Catalysis; Song, C., Ed.; Academic Press: Cambridge, MA, USA, 2017; Volume 60, pp. 59-123.

72. Malkin, A.Y.; Isayev, A.I. Applications of rheology. In Rheology Concepts, Methods, and Applications; Malkin, A.Y., Isayev, A.I., Eds.; Elsevier: Oxford, UK, 2012; pp. 365-420. 
73. Afshari, M.; Kotek, R.; Tonelli, A.E.; Jung, D.W. Producing polyamide nanofibers by electrospinning. In Nanofibers and Nanotechnology in Textiles; Brown, P.J., Stevens, K., Eds.; Woodhead Publishing: Sawston, UK, 2007; pp. 71-89.

74. Pedicini, A.; Farris, R.J. Thermally induced color change in electrospun fiber mats. J. Polym. Sci. Part B Polym. Phys. 2004, 42, 752-757. [CrossRef]

75. Deitzel, J.M.; Kosik, W.; McKnight, S.H.; Tan, N.C.B.; DeSimone, J.M.; Crette, S. Electrospinning of polymer nanofibers with specific surface chemistry. Polymer 2002, 43, 1025-1029. [CrossRef]

76. Fitzer, E.; Manocha, L.M. Carbon Reinforcements and Carbon/Carbon Composites; Springer Science \& Business Media: Berlin, Germany, 2012.

77. Wheatley, A.; Warren, D.; Das, S. Low-cost carbon fibre: Applications, performance and cost models. Adv. Compos. Mater. Automotive Appl. 2013, 405-434. [CrossRef]

78. Sudo, K.; Shimizu, K. A new carbon-fiber from lignin. J. Appl. Polym. Sci. 1992, 44, 127-134. [CrossRef]

79. Wang, S.; Zhou, Z.; Xiang, H.; Chen, W.; Yin, E.; Chang, T.; Zhu, M. Reinforcement of lignin-based carbon fibers with functionalized carbon nanotubes. Compos. Sci. Technol. 2016, 128, 116-122. [CrossRef]

80. Wang, S.; Li, Y.; Xiang, H.; Zhou, Z.; Chang, T.; Zhu, M. Low cost carbon fibers from bio-renewable Lignin/Poly(lactic acid) (PLA) blends. Compos. Sci. Technol. 2015, 119, 20-25. [CrossRef]

81. Alexy, P.; Kosikova, B.; Podstranska, G. The effect of blending lignin with polyethylene and polypropylene on physical properties. Polymer 2000, 41, 4901-4908. [CrossRef]

82. Kadla, J.F.; Kubo, S.; Venditti, R.A.; Gilbert, R.D.; Compere, A.L.; Griffith, W. Lignin-based carbon fibers for composite fiber applications. Carbon 2002, 40, 2913-2920. [CrossRef]

83. Thunga, M.; Chen, K.; Grewell, D.; Kessler, M.R. Bio-renewable precursor fibers from lignin/polylactide blends for conversion to carbon fibers. Carbon 2014, 68, 159-166. [CrossRef]

84. Zhang, M.; Ogale, A.A. Carbon fibers derived from acetylated softwood kraft lignin. Polym. Precursor Deriv. Carbon 2014, $1173,137-152$.

85. Sudo, K.; Shimizu, K.; Nakashima, N.; Yokoyama, A. A new modification method of exploded lignin for the preparation of a carbon fiber precursor. J. Appl. Polym. Sci. 1993, 48, 1485-1491. [CrossRef]

86. Ziabicki, A. Studies on the orientation phenomena by fiber formation from polymer melts. Part II. Theoretical considerations. J. Appl. Polym. Sci. 1960, 4, 24-31. [CrossRef]

87. Heuvel, H.M.; Huisman, R. Effect of winding speed on the physical structure of as-spun poly(ethylene terephthalate) fibers, including orientation-induced crystallization. J. Appl. Polym. Sci. 1978, 22, 2229-2243. [CrossRef]

88. Jin, J.; Ding, J.; Klett, A.S.; Thies, M.C.; Ogale, A.A. Carbon fibers derived from fractionated-solvated lignin precursors for enhanced mechanical performance. ACS Sustain. Chem. Eng. 2018, 6, 14135-14142. [CrossRef]

89. Yoon, H. Melt Spinning of High Performance Poly(ethylene terephthalate) (PET) Multifilament Yarn via Utilizing a Horizontal Isothermal Bath (HIB) in the Threadline; North Carolina State University: Raleigh, NC, USA, 2012.

90. Compere, A.L.; Griffith, W.L.; Leitten, C.F.; Shaffer, J.T. Low cost carbon fiber from renewable resources. Adv. Afford. Mater. Technol. 2001, 33, 1306-1314.

91. Qin, W.; Kadla, J.F. Carbon fibers based on pyrolytic lignin. J. Appl. Polym. Sci. 2012, 126, E204-E213. [CrossRef]

92. Uraki, Y.; Kubo, S.; Nigo, N.; Sano, Y.; Sasaya, T. Preparation of carbon-fibers from organosolv lignin obtained by aqueous acetic-acid pulping. Holzforschung 1995, 49, 343-350. [CrossRef]

93. Thielemans, W.; Wool, R.P. Lignin esters for use in unsaturated thermosets: Lignin modification and solubility modeling. Biomacromolecules 2005, 6, 1895-1905. [CrossRef]

94. Culebras, M.; Beaucamp, A.; Wang, Y.; Clauss, M.M.; Frank, E.; Collins, M.N. Biobased Structurally Compatible Polymer Blends Based on Lignin and Thermoplastic Elastomer Polyurethane as Carbon Fiber Precursors. ACS Sustain. Chem. Eng. 2018, 6, 8816-8825. [CrossRef]

95. Hosseinaei, O.; Harper, D.P.; Bozell, J.J.; Rials, T.G. Improving Processing and Performance of Pure Lignin Carbon Fibers through Hardwood and Herbaceous Lignin Blends. Int. J. Mol. Sci. 2017, 18, 1410. [CrossRef]

96. Nordström, Y.; Norberg, I.; Sjöholm, E.; Drougge, R. A new softening agent for melt spinning of softwood kraft lignin. J. Appl. Polym. Sci. 2013, 129, 1274-1279. [CrossRef]

97. Qu, W.; Liu, J.; Xue, Y.; Wang, X.; Bai, X. Potential of producing carbon fiber from biorefinery corn stover lignin with high ash content. J. Appl. Polym. Sci. 2018, 135, 45736. [CrossRef]

98. Qu, W.; Xue, Y.; Gao, Y.; Rover, M.; Bai, X. Repolymerization of pyrolytic lignin for producing carbon fiber with improved properties. Biomass Bioenergy 2016, 95, 19-26. [CrossRef]

99. Luo, Y.; Qu, W.; Cochran, E.; Bai, X. Enabling high-quality carbon fiber through transforming lignin into an orientable and melt-spinnable polymer. J. Clean. Prod. 2021, 307, 127252. [CrossRef]

100. Kubo, S.; Uraki, Y.; Sano, Y. Preparation of carbon fibers from softwood lignin by atmospheric acetic acid pulping. Carbon 1998, 36, 1119-1124. [CrossRef]

101. Chen, K. Bio-Renewable Fibers Extracted from Lignin/Polylactide (PLA) Blend; Iowa State University: Ames, IA, USA, 2012.

102. Beaucamp, A.; Wang, Y.; Culebras, M.; Collins, M.N. Carbon fibres from renewable resources: The role of the lignin molecular structure in its blendability with biobased poly(ethylene terephthalate). Green Chem. 2019, 21, 5063-5072. [CrossRef] 
103. Lin, J.; Kubo, S.; Yamada, T.; Koda, K.; Uraki, Y. Chemical thermostabilization for the preparation of carbon fibers from softwood lignin. Bioresources 2012, 7, 13. [CrossRef]

104. Kleinhans, H.; Salmén, L. Development of lignin carbon fibers: Evaluation of the carbonization process. J. Appl. Polym. Sci. 2016, 133. [CrossRef]

105. Baker, D.A.; Gallego, N.C.; Baker, F.S. On the characterization and spinning of an organic-purified lignin toward the manufacture of low-cost carbon fiber. J. Appl. Polym. Sci. 2012, 124, 227-234. [CrossRef]

106. Klett, A.S.; Chappell, P.V.; Thies, M.C. Recovering ultraclean lignins of controlled molecular weight from Kraft black-liquor lignins. Chem. Commun. 2015, 51, 12855-12858. [CrossRef] [PubMed]

107. Klett, A.S.; Payne, M.; Thies, M.C. Continuous-flow process for the purification and fractionation of alkali and Organosolv lignins. ACS Sustain. Chem. Eng. 2016, 4, 6689-6694. [CrossRef]

108. Thies, M.C.; Klett, A.S.; Bruce, D.A. Solvent and Recovery Process for Lignin. U.S. Patent 10,053,482, 21 August 2018.

109. Liu, L.Y.; Hua, Q.; Renneckar, S. A simple route to synthesize esterified lignin derivatives. Green Chem. 2019, $21,3682-3692$. [CrossRef]

110. Buono, P.; Duval, A.; Verge, P.; Averous, L.; Habibi, Y. New insights on the chemical modification of lignin: Acetylation versus silylation. ACS Sustain. Chem. Eng. 2016, 4, 5212-5222. [CrossRef]

111. Soutis, C. Carbon fiber reinforced plastics in aircraft construction. Mater. Sci. Eng. 2005, 412, 171-176. [CrossRef]

112. Kadla, J.F.; Kubo, S. Lignin-based polymer blends: Analysis of intermolecular interactions in lignin-synthetic polymer blends. Compos. Part A Appl. Sci. Manuf. 2004, 35, 395-400. [CrossRef]

113. Kadla, J.F.; Kubo, S.; Venditti, R.A.; Gilbert, R.D. Novel hollow core fibers prepared from lignin polypropylene blends. J. Appl. Polym. Sci. 2002, 85, 1353-1355. [CrossRef]

114. Baker, F.; Menchhofer, P. Carbon Nanotube (CNT) Enhanced Precursor for Carbon Fiber Production and Method of Making a CNT Enhanced Continuous Lignin Fiber. U.S. Patent 2011285049, 24 November 2011.

115. Kubo, S.; Yoshida, T.; Kadla, J.F. Surface porosity of lignin/PP Blend carbon fibers. J. Wood Chem. Technol. 2007, $27,257-271$. [CrossRef]

116. Zhang, M.; Jin, J.; Ogale, A. Carbon fibers from UV-assisted stabilization of lignin-based precursors. Fibers 2015, 3, 184-196. [CrossRef]

117. Oroumei, A.; Lynch, P.; Tobin, M.; Naebe, M. Synchrotron X-ray scattering and IR-mapping studies of wet-spun lignin-derived carbon fibre precursor. Compos. Sci. Technol. 2018, 163, 151-161. [CrossRef]

118. Dong, X.; Lu, C.; Zhou, P.; Zhang, S.; Wang, L.; Li, D. Polyacrylonitrile/lignin sulfonate blend fiber for low-cost carbon fiber. RSC Adv. 2015, 5, 42259-42265. [CrossRef]

119. Maradur, S.P.; Kim, C.H.; Kim, S.Y.; Kim, B.H.; Kim, W.C.; Yang, K.S. Preparation of carbon fibers from a lignin copolymer with polyacrylonitrile. Synth. Met. 2012, 162, 453-459. [CrossRef]

120. Blades, H. Dry Jet Wet Spinning Process. U.S. Patent 3,767,756, 23 October 1973.

121. Khayyam, H.; Jazar, R.N.; Nunna, S.; Golkarnarenji, G.; Badii, K.; Fakhrhoseini, S.M.; Kumar, S.; Naebe, M. PAN precursor fabrication, applications and thermal stabilization process in carbon fiber production: Experimental and mathematical modelling. Prog. Mater. Sci. 2020, 107, 100575. [CrossRef]

122. Lewin, M. Handbook of Fiber Chemistry; CRC Press: Boca Raton, FL, USA, 2006.

123. Liu, H.; Chien, A.T.; Newcomb, B.A.; Liu, Y.; Kumar, S. Processing, structure, and properties of lignin- and CNT-incorporated polyacrylonitrile-based carbon fibers. ACS Sustain. Chem. Eng. 2015, 3, 1943-1954. [CrossRef]

124. Lu, C.; Blackwell, C.; Ren, Q.; Ford, E. Effect of the coagulation bath on the structure and mechanical properties of gel-spun lignin/poly(vinyl alcohol) fibers. ACS Sustain. Chem. Eng. 2017, 5, 2949-2959. [CrossRef]

125. Lu, C.; Rawat, P.; Louder, N.; Ford, E. Properties and structural anisotropy of gel-spun lignin/poly(vinyl alcohol) fibers due to gel aging. ACS Sustain. Chem. Eng. 2018, 6, 679-689. [CrossRef]

126. Liu, H.; Luo, J.; Chang, H.; Davijani, A.A.B.; Wang, P.; Kumar, S. Polyacrylonitrile sheath and polyacrylonitrile/lignin core bi-component carbon fibers. Carbon 2019, 149, 165-172. [CrossRef]

127. Smith, P.; Lemstra, P.J.; Booij, H.C. Ultradrawing of high-molecular-weight polyethylene cast from solution. II. Influence of initial polymer concentration. J. Polym. Sci. Polym. Phys. Ed. 1981, 19, 877-888. [CrossRef]

128. Kuo, C.J.; Lan, W.L. Gel spinning of synthetic polymer fibres. In Advances in Filament Yarn Spinning of Textiles and Polymers; Zhang, D., Ed.; Woodhead Publishing: Sawston, UK, 2014; pp. 100-112.

129. Chen, H.; Du, W.; Ye, W.; Pan, D. Structure of PAN precursor in thermal-induced gel spinning. J. Appl. Polym. Sci. 2011, 122, 1176-1181. [CrossRef]

130. Le, N.D.; Trogen, M.; Varley, R.J.; Hummel, M.; Byrne, N. Effect of boric acid on the stabilisation of cellulose-lignin filaments as precursors for carbon fibres. Cellulose 2021, 28, 729-739. [CrossRef]

131. Xia, K.; Ouyang, Q.; Chen, Y.; Wang, X.; Qian, X.; Wang, L. Preparation and characterization of lignosulfonate-acrylonitrile copolymer as a novel carbon fiber precursor. ACS Sustain. Chem. Eng. 2015, 4, 159-168. [CrossRef] 
132. Ouyang, Q.; Xia, K.; Liu, D.; Jiang, X.; Ma, H.; Chen, Y. Fabrication of partially biobased carbon fibers from novel lignosulfonateacrylonitrile copolymers. J. Mater. Sci. 2017, 52, 7439-7451. [CrossRef]

133. Husman, G. Development and Commercialization of a Novel Low-Cost Carbon Fiber. Presentation at 2014 DOE Hydrogen and Fuel Cells Program and Vehicle Technologies Program Annual Merit Review and Peer Evaluation Meeting. 17 June 2014. Available online: https://www.energy.gov/sites/prod/files/2014/07/f17/lm048_husman_2014_o_0.pdf (accessed on 1 May 2021).

134. Park, C.W.; Youe, W.J.; Han, S.Y.; Kim, Y.S.; Lee, S.H. Solubility of kraft lignin-g-polyacrylonitrile copolymer in various ionic liquids and characterization of its solution. Wood Sci. Technol. 2017, 51, 151-163. [CrossRef]

135. Jin, J.; Ogale, A.A. Carbon fibers derived from wet-spinning of equi-component lignin/polyacrylonitrile blends. J. Appl. Polym. Sci. 2018, 135. [CrossRef]

136. Bengtsson, A.; Bengtsson, J.; Olsson, C.; Sedin, M.; Jedvert, K.; Theliander, H.; Sjoholm, E. Improved yield of carbon fibres from cellulose and kraft lignin. Holzforschung 2018, 72, 1007-1016. [CrossRef]

137. Follmer, M.; Jestin, S.; Neri, W.; Derre, A.; Bentaleb, A.; Mercader, C.; Poulin, P. Structuration of lignin-graphene oxide based carbon materials through liquid crystallinity. Carbon 2019, 149, 297-306. [CrossRef]

138. Follmer, M.; Jestin, S.; Neri, W.; Vo, V.; Derre, A.; Mercader, C.; Poulin, P. Wet-spinning and carbonization of lignin-polyvinyl alcohol precursor fibers. Adv. Sustain. Syst. 2019, 3, 1900082. [CrossRef]

139. Trogen, M.; Le, N.D.; Sawada, D.; Guizani, C.; Lourencon, T.V.; Pitkanen, L.; Sixta, H.; Shah, R.; O’Neill, H.; Balakshin, M.; et al. Cellulose-lignin composite fibres as precursors for carbon fibres. Part 1-Manufacturing and properties of precursor fibres. Carbohydr. Polym. 2021, 252, 117133. [CrossRef]

140. Bengtsson, A.; Hecht, P.; Sommertune, J.; Ek, M.; Sedin, M.; Sjöholm, E. Carbon fibers from lignin-cellulose precursors: Effect of carbonization conditions. ACS Sustain. Chem. Eng. 2020, 8, 6826-6833. [CrossRef]

141. Nypelo, T.; Asaadi, S.; Kneidinger, G.; Sixta, H.; Konnerth, J. Conversion of wood-biopolymers into macrofibers with tunable surface energy via dry-jet wet-spinning. Cellulose 2018, 25, 5297-5307. [CrossRef] [PubMed]

142. Ramasubramanian, G. Influence of Lignin Modification on PAN-Lignin Copolymers as Potential Carbon Fiber Precursors; Iowa State University: Ames, IA, USA, 2013.

143. Husman, G. Development and Commercialization of a Novel Low-Cost Carbon Fiber. Presentation at 2013 DOE Hydrogen and Fuel Cells Program and Vehicle Technologies Program Annual Merit Review and Peer Evaluation Meeting. 15 May 2013. Available online: https:/ / www.energy.gov/sites/prod/files/2014/03/f10/lm048_husman_2013_o_0.pdf (accessed on 1 May 2021).

144. Jiang, X.; Ouyang, Q.; Liu, D.; Huang, J.; Ma, H.; Chen, Y.; Wang, X.; Sun, W. Preparation of low-cost carbon fiber precursors from blends of wheat straw lignin and commercial textile-grade polyacrylonitrile (PAN). Holzforschung 2018, 72, 727-734. [CrossRef]

145. Zhang, B.; Lu, C.; Liu, Y.; Zhou, P. Wet spun polyacrylontrile-based hollow fibers by blending with alkali lignin. Polymer 2018, 149, 294-304. [CrossRef]

146. Jia, Z.; Lu, C.; Liu, Y.; Zhou, P.; Wang, L. Lignin/polyacrylonitrile composite hollow fibers prepared by wet spinning method. ACS Sustain. Chem. Eng. 2016, 4, 2838-2842. [CrossRef]

147. He, Q.; Zhou, P.; Hao, J.; Lu, C.; Liu, Y. Incorporation of alkali lignin in polyacrylonitrile: Phase separation, coagulation, and cyclization kinetics. ACS Omega 2019, 4, 11346-11353. [CrossRef]

148. Porkodi, P.; Abhilash, J.K.; Shukla, H.K.; Rawat, J. Rheological properties of concentrated polyacrylonitrile co-polymer and lignin blend solution. Polym. Bull. 2020, 77, 3937-3951. [CrossRef]

149. Liu, H.C.; Tuan, C.C.; Davijani, A.A.B.; Wang, P.H.; Chang, H.; Wong, C.P.; Kumar, S. Rheological behavior of polyacrylonitrile and polyacrylonitrile/lignin blends. Polymer 2017, 111, 177-182. [CrossRef]

150. Song, L.; Ouyang, Q.; Huang, X.; Ma, H.; Chen, P.; Shen, L.; Wang, X. Carbon fibers with low cost and uniform disordered structure derived from lignin/polyacrylonitrile composite precursors. Fibers Polym. 2021, 22, 240-248. [CrossRef]

151. Cha, W.I.; Hyon, S.H.; Ikada, Y. Gel spinning of poly(vinyl alcohol) from dimethyl sulfoxide/water mixture. J. Polym. Sci. Pol. Phys. 1994, 32, 297-304. [CrossRef]

152. Yamaura, K.; Tanigami, T.; Hayashi, N.; Kosuda, K.; Okuda, S.; Takemura, Y.; Itoh, M.; Matsuzawa, S. Preparation of high modulus poly(vinyl alcohol) by drawing. J. Appl. Polym. Sci. 1990, 40, 905-916. [CrossRef]

153. Bengtsson, A.; Bengtsson, J.; Sedin, M.; Sjoholm, E. Carbon fibers from lignin-cellulose precursors: Effect of stabilization conditions. ACS Sustain. Chem. Eng. 2019, 7, 8440-8448. [CrossRef]

154. Olsson, C.; Sjöholm, E.; Reimann, A. Carbon fibres from precursors produced by dry-jet wet-spinning of kraft lignin blended with kraft pulps. Holzforschung 2017, 71, 275-283. [CrossRef]

155. Le, N.D.; Trogen, M.; Ma, Y.; Varley, R.J.; Hummel, M.; Byrne, N. Cellulose-lignin composite fibers as precursors for carbon fibers: Part 2-The impact of precursor properties on carbon fibers. Carbohydr. Polym. 2020, 250, 116918. [CrossRef]

156. Le, N.D.; Trogen, M.; Ma, Y.B.; Varley, R.J.; Hummel, M.; Byrne, N. Understanding the influence of key parameters on the stabilisation of cellulose-lignin composite fibres. Cellulose 2021, 28, 911-919. [CrossRef]

157. Byrne, N.; De Silva, R.; Ma, Y.; Sixta, H.; Hummel, M. Enhanced stabilization of cellulose-lignin hybrid filaments for carbon fiber production. Cellulose 2018, 25, 723-733. [CrossRef]

158. Svenningsson, L.; Bengtsson, J.; Jedvert, K.; Schlemmer, W.; Theliander, H.; Evenas, L. Disassociated molecular orientation distributions of a composite cellulose-lignin carbon fiber precursor: A study by rotor synchronized NMR spectroscopy and X-ray scattering. Carbohydr. Polym. 2021, 254, 117293. [CrossRef] 
159. Wang, L.; Ago, M.; Borghei, M.; Ishaq, A.; Papageorgiou, A.C.; Lundahl, M.; Rojas, O.J. Conductive carbon microfibers derived from wet-spun lignin/nanocellulose hydrogels. ACS Sustain. Chem. Eng. 2019, 7, 6013-6022. [CrossRef]

160. Vincent, S.; Prado, R.; Kuzmina, O.; Potter, K.; Bhardwaj, J.; Wanasekara, N.D.; Harniman, R.L.; Koutsomitopoulou, A.; Eichhorn, S.J.; Welton, T.; et al. Regenerated cellulose and willow lignin blends as potential renewable precursors for carbon fibers. ACS Sustain. Chem. Eng. 2018, 6, 5903-5910. [CrossRef]

161. Torres-Canas, F.; Bentaleb, A.; Follmer, M.; Roman, J.; Neri, W.; Ly, I.; Derre, A.; Poulin, P. Improved structure and highly conductive lignin-carbon fibers through graphene oxide liquid crystal. Carbon 2020, 163, 120-127. [CrossRef]

162. Svinterikos, E.; Zuburtikudis, I. Carbon nanofibers from renewable bioresources (lignin) and a recycled commodity polymer [poly(ethylene terephthalate)]. J. Appl. Polym. Sci. 2016, 133. [CrossRef]

163. Youe, W.J.; Lee, S.M.; Lee, S.S.; Lee, S.H.; Kim, Y.S. Characterization of carbon nanofiber mats produced from electrospun lignin-g-polyacrylonitrile copolymer. Int. J. Biol. Macromol. 2016, 82, 497-504. [CrossRef]

164. Ruiz-Rosas, R.; Bedia, J.; Lallave, M.; Loscertales, I.G.; Barrero, A.; Rodriguez-Mirasol, J.; Cordero, T. The production of submicron diameter carbon fibers by the electrospinning of lignin. Carbon 2010, 48, 696-705. [CrossRef]

165. Xu, X.; Zhou, J.; Jiang, L.; Lubineau, G.; Payne, S.A.; Gutschmidt, D. Lignin-based carbon fibers: Carbon nanotube decoration and superior thermal stability. Carbon 2014, 80, 91-102. [CrossRef]

166. Svinterikos, E.; Zuburtikudis, I.; Al-Marzouqi, M. The nanoscale dimension determines the carbonization outcome of electrospun lignin/recycled-PET fibers. Chem. Eng. Sci. 2019, 202, 26-35. [CrossRef]

167. Li, Q.; Naik, M.T.; Lin, H.S.; Hu, C.; Serem, W.K.; Liu, L.; Karki, P.; Zhou, F.; Yuan, J. Tuning hydroxyl groups for quality carbon fiber of lignin. Carbon 2018, 139, 500-511. [CrossRef]

168. Wang, S.; Innocent, M.T.; Chen, J.; Wang, Q.; Ma, W.; Tang, J. Tuning the microstructure and electrochemical behavior of lignin-based ultrafine carbon fibers via hydrogen-bonding interaction. Int. J. Biol. Macromol. 2020, 157, 706-714. [CrossRef]

169. Ding, R.; Wu, H.; Thunga, M.; Bowler, N.; Kessler, M.R. Processing and characterization of low-cost electrospun carbon fibers from organosolv lignin/polyacrylonitrile blends. Carbon 2016, 100, 126-136. [CrossRef]

170. Lallave, M.; Bedia, J.; Ruiz-Rosas, R.; Rodriguez-Mirasol, J.; Cordero, T.; Otero, J.C.; Marquez, M.; Barrero, A.; Loscertales, I.G. Filled and hollow carbon nanofibers by coaxial electrospinning of Alcell lignin without binder polymers. Adv. Mater. 2007, 19, 4292-4296. [CrossRef]

171. Deitzel, J.M.; Kleinmeyer, J.; Harris, D.; Tan, N.C.B. The effect of processing variables on the morphology of electrospun nanofibers and textiles. Polymer 2001, 42, 261-272. [CrossRef]

172. Prabu, G.T.V.; Dhurai, B. A novel profiled multi-pin electrospinning system for nanofiber production and encapsulation of nanoparticles into nanofibers. Sci. Rep. 2020, 10, 4302. [CrossRef]

173. Garcia-Mateos, F.J.; Ruiz-Rosas, R.; Rosas, J.M.; Rodriguez-Mirasol, J.; Cordero, T. Controlling the composition, morphology, porosity, and surface chemistry of lignin-based electrospun carbon materials. Front. Mater. 2019, 6, 114. [CrossRef]

174. Li, Z.; Wang, C. Effects of working parameters on electrospinning. In One-Dimensional Nanostructures: Electrospinning Technique and Unique Nanofibers; Li, Z., Wang, C., Eds.; Springer: Berlin/Heidelberg, Germany, 2013; pp. 15-28.

175. Teo, W.E.; Inai, R.; Ramakrishna, S. Technological advances in electrospinning of nanofibers. Sci. Technol. Adv. Mater. 2011, 12, 013002. [CrossRef]

176. Han, D.; Steckl, A.J. Coaxial electrospinning formation of complex polymer fibers and their applications. ChemPlusChem 2019, 84, 1453-1497. [CrossRef] [PubMed]

177. Liu, L.; Xu, W.H.; Ding, Y.C.; Agarwal, S.; Greiner, A.; Duan, G.G. A review of smart electrospun fibers toward textiles. Compos. Commun. 2020, 22, 100506. [CrossRef]

178. Azwar, E.; Wan Mahari, W.A.; Chuah, J.H.; Vo, D.V.N.; Ma, N.L.; Lam, W.H.; Lam, S.S. Transformation of biomass into carbon nanofiber for supercapacitor application-A review. Int. J. Hydrog. Energ. 2018, 43, 20811-20821. [CrossRef]

179. Dallmeyer, I.; Ko, F.; Kadla, J.F. Electrospinning of technical Lignins for the production of fibrous networks. J. Wood Chem. Technol. 2010, 30, 315-329. [CrossRef]

180. Poursorkhabi, V.; Abdelwahab, M.A.; Misra, M.; Khalil, H.; Gharabaghi, B.; Mohanty, A.K. Processing, carbonization, and characterization of lignin based electrospun carbon Fibers: A review. Front. Energy Res. 2020, 8. [CrossRef]

181. Garcia-Mateos, F.J.; Cordero-Lanzac, T.; Berenguer, R.; Morallon, E.; Cazorla-Amoros, D.; Rodriguez-Mirasol, J.; Cordero, T. Lignin-derived Pt supported carbon (submicron)fiber electrocatalysts for alcohol electro-oxidation. Appl. Catal. B Environ. 2017, 211, 18-30. [CrossRef]

182. Garcia-Mateos, F.J.; Berenguer, R.; Valero-Romero, M.J.; Rodriguez-Mirasol, J.; Cordero, T. Phosphorus functionalization for the rapid preparation of highly nanoporous submicron-diameter carbon fibers by electrospinning of lignin solutions. J. Mater. Chem. A 2018, 6, 1219-1233. [CrossRef]

183. Mikes, P.; Baker, D.A.; Uhlin, A.; Lukas, D.; Kuzelova-Kostakova, E.; Vidrich, A.; Valtera, J.; Koprivova, B.; Asatiani, N.; Salmen, L.; et al. The mass production of lignin fibres by means of needleless electrospinning. J. Polym. Environ. 2021. [CrossRef]

184. You, X.; Koda, K.; Yamada, T.; Uraki, Y. Preparation of electrode for electric double layer capacitor from electrospun lignin fibers. Holzforschung 2015, 69, 1097-1106. [CrossRef]

185. Schlee, P.; Hosseinaei, O.; Baker, D.; Landmer, A.; Tomani, P.; Mostazo-Lopez, M.J.; Cazorla-Amoros, D.; Herou, S.; Titirici, M.M. From waste to wealth: From Kraft lignin to free-standing supercapacitors. Carbon 2019, 145, 470-480. [CrossRef] 
186. Lai, C.; Zhou, Z.; Zhang, L.; Wang, X.; Zhou, Q.; Zhao, Y.; Wang, Y.; Wu, X.; Zhu, Z.; Fong, H. Free-standing and mechanically flexible mats consisting of electrospun carbon nanofibers made from a natural product of alkali lignin as binder-free electrodes for high-performance supercapacitors. J. Power Sources 2014, 247, 134-141. [CrossRef]

187. Shi, X.; Wang, X.; Tang, B.; Dai, Z.; Chen, K.; Zhou, J. Impact of lignin extraction methods on microstructure and mechanical properties of lignin-based carbon fibers. J. Appl. Polym. Sci. 2018, 135, 45580. [CrossRef]

188. Shi, X.; Dai, Z.; Cao, Q.; Chen, K.; Zhou, J. Stepwise fractionation extracted lignin for high strength lignin-based carbon fibers. New J. Chem. 2019, 43, 18868-18875. [CrossRef]

189. Cho, M.J.; Karaaslan, M.A.; Renneckar, S.; Ko, F. Enhancement of the mechanical properties of electrospun lignin-based nanofibers by heat treatment. J. Mater. Sci. 2017, 52, 9602-9614. [CrossRef]

190. Dallmeyer, I.; Lin, L.T.; Li, Y.; Ko, F.; Kadla, J.F. Preparation and characterization of interconnected, kraft lignin-based carbon fibrous materials by electrospinning. Macromol. Mater. Eng. 2014, 299, 540-551. [CrossRef]

191. Ghosh, T.; Chen, J.W.; Kumar, A.; Tang, T.; Ayranci, C. Bio-cleaning improves the mechanical properties of lignin-based carbon fibers. RSC Adv. 2020, 10, 22983-22995. [CrossRef]

192. Cho, M.; Karaaslan, M.; Chowdhury, S.; Ko, F.; Renneckar, S. Skipping oxidative thermal stabilization for lignin-based carbon nanofibers. ACS Sustain. Chem. Eng. 2018, 6, 6434-6444. [CrossRef]

193. Liu, H.; Dai, Z.; Cao, Q.; Shi, X.J.; Wang, X.; Li, H.; Han, Y.; Li, Y.; Zhou, J. Lignin/polyacrylonitrile carbon fibers: The effect of fractionation and purification on properties of derived carbon fibers. ACS Sustain. Chem. Eng. 2018, 6, 8554-8562. [CrossRef]

194. Dai, Z.; Shi, X.; Liu, H.; Li, H.; Han, Y.; Zhou, J. High-strength lignin-based carbon fibers via a low-energy method. RSC Adv. 2018, 8, 1218-1224. [CrossRef]

195. Zhang, R.; Du, Q.; Wang, L.; Zheng, Z.; Guo, L.; Zhang, X.; Yang, X.; Yu, H. Unlocking the response of lignin structure for improved carbon fiber production and mechanical strength. Green Chem. 2019, 21, 4981-4987. [CrossRef]

196. Zhang, X.; Dong, S.; Wu, W.; Yang, J.; Li, J.; Shi, K.; Liu, H. Influence of lignin units on the properties of lignin/PAN-derived carbon fibers. J. Appl. Polym. Sci. 2020, 137, 49274. [CrossRef]

197. Dai, Z.; Ren, P.G.; An, Y.L.; Zhang, H.; Ren, F.; Zhang, Q. Nitrogen-sulphur co-doped graphenes modified electrospun lignin/polyacrylonitrile-based carbon nanofiber as high performance supercapacitor. J. Power Sources 2019, 437, 226937. [CrossRef]

198. Park, C.W.; Youe, W.J.; Han, S.Y.; Kim, Y.S.; Lee, S.H. Characteristics of carbon nanofibers produced from lignin/polyacrylonitrile (PAN)/kraft lignin-g-PAN copolymer blends electrospun nanofibers. Holzforschung 2017, 71, 743-750. [CrossRef]

199. Du, B.; Chen, C.; Sun, Y.; Yu, M.; Liu, B.; Wang, X.; Zhou, J. Lignin bio-oil-based electrospun nanofibers with high substitution ratio property for potential carbon nanofibers applications. Polym. Test. 2020, 89, 106591. [CrossRef]

200. Beck, R.J.; Zhao, Y.; Fong, H.; Menkhaus, T.J. Electrospun lignin carbon nanofiber membranes with large pores for highly efficient adsorptive water treatment applications. J. Water Process. Eng. 2017, 16, 240-248. [CrossRef]

201. Roman, J.; Neri, W.; Derre, A.; Poulin, P. Electrospun lignin-based twisted carbon nanofibers for potential microelectrodes applications. Carbon 2019, 145, 556-564. [CrossRef]

202. Schreiber, M.; Vivekanandhan, S.; Mohanty, A.K.; Misra, M. Iodine treatment of lignin-cellulose acetate electrospun fibers: Enhancement of green fiber carbonization. ACS Sustain. Chem. Eng. 2014, 3, 33-41. [CrossRef]

203. Xu, X.; Zhou, J.; Jiang, L.; Lubineau, G.; Chen, Y.; Wu, X.F.; Piere, R. Porous core-shell carbon fibers derived from lignin and cellulose nanofibrils. Mater. Lett. 2013, 109, 175-178. [CrossRef]

204. Ma, C.; Li, Z.; Li, J.; Fan, Q.; Wu, L.; Shi, J.; Song, Y. Lignin-based hierarchical porous carbon nanofiber films with superior performance in supercapacitors. Appl. Surf. Sci. 2018, 456, 568-576. [CrossRef]

205. Cao, M.; Cheng, W.; Ni, X.; Hu, Y.; Han, G. Lignin-based multi-channels carbon nanofibers @ SnO2 nanocomposites for highperformance supercapacitors. Electrochim. Acta 2020, 345, 136172. [CrossRef]

206. Badrossamay, M.R.; McIlwee, H.A.; Goss, J.A.; Parker, K.K. Nanofiber assembly by rotary jet-spinning. Nano Lett. 2010, 10, 2257-2261. [CrossRef]

207. Sarkar, K.; Gomez, C.; Zambrano, S.; Ramirez, M.; de Hoyos, E.; Vasquez, H.; Lozano, K. Electrospinning to forcespinning ${ }^{\mathrm{TM}}$. Mater. Today 2010, 13, 12-14. [CrossRef]

208. Stojanovska, E.; Kurtulus, M.; Abdelgawad, A.; Candan, Z.; Kilic, A. Developing lignin-based bio-nanofibers by centrifugal spinning technique. Int. J. Biol. Macromol. 2018, 113, 98-105. [CrossRef]

209. Wong, E.W.; Sheehan, P.E.; Lieber, C.M. Nanobeam mechanics: Elasticity, strength, and toughness of nanorods and nanotubes. Science 1997, 277, 1971-1975. [CrossRef]

210. Yu, M.F.; Lourie, O.; Dyer, M.J.; Moloni, K.; Kelly, T.F.; Ruoff, R.S. Strength and breaking mechanism of multiwalled carbon nanotubes under tensile load. Science 2000, 287, 637-640. [CrossRef]

211. Lee, C.; Wei, X.; Kysar, J.W.; Hone, J. Measurement of the elastic properties and intrinsic strength of monolayer graphene. Science 2008, 321, 385-388. [CrossRef]

212. Tian, D.; Hu, J.; Bao, J.; Chandra, R.P.; Saddler, J.N.; Lu, C. Lignin valorization: Lignin nanoparticles as high-value bio-additive for multifunctional nanocomposites. Biotechnol. Biofuels 2017, 10, 192. [CrossRef]

213. Hu, M.; Chen, Z.; Luo, S.; Yang, X.; Ye, R.; Zheng, M.; Chen, P. Preparation of graphene oxide and alkali lignin nanohybrids and its application to reinforcing polymer. Wood Sci. Technol. 2019, 53, 649-664. [CrossRef]

214. Zhao, G.; Ni, H.; Ren, S.; Fang, G. Correlation between Solubility Parameters and Properties of Alkali Lignin/PVA Composites. Polymers 2018, 10, 290. [CrossRef] [PubMed] 
215. Rejmontova, P.; Kovalcik, A.; Humpolicek, P.; Capakova, Z.; Wrzecionko, E.; Saha, P. The use of fractionated Kraft lignin to improve the mechanical and biological properties of PVA-based scaffolds. RSC Adv. 2019, 9, 12346-12353. [CrossRef]

216. Kwak, H.W.; Woo, H.; Kim, E.H.; Lee, K.H. Water-resistant Lignin/Poly(vinyl alcohol) Blend Fibers for Removal of Hexavalent Chromium. Fibers Polym. 2018, 19, 1175-1183. [CrossRef]

217. Porkodi, P.; Abhilash, J.K.; Sunil, S.; Pardhi, T.K.; Shukla, H.K.; Shete, S.K.; Kumar, A. Lignin addition to polyacrylonitrile copolymer solution and its effect on the properties of carbon fiber precursor. J. Polym. Res. 2021, 28, 1-9. [CrossRef]

218. Al Aiti, M.; Das, A.; Kanerva, M.; Jarventausta, M.; Johansson, P.; Scheffler, C.; Gobel, M.; Jehnichen, D.; Brunig, H.; Wulff, L.; et al. Dry-jet wet spinning of thermally stable lignin-textile grade polyacrylonitrile fibers regenerated from chloride-based ionic liquids compounds. Materials 2020, 13, 3687. [CrossRef]

219. Zhang, B.; Lu, C.; Liu, Y.; Zhou, P.; Yu, Z.; Yuan, S. Wet spun polyacrylonitrile-based hollow-mesoporous fibers with different draw ratios. Polymer 2019, 179, 121618. [CrossRef]

220. Pouteau, C.; Baumberger, S.; Cathala, B.; Dole, P. Lignin-polymer blends: Evaluation of compatibility by image analysis. Comptes Rendus Biol. 2004, 327, 935-943. [CrossRef]

221. Kubo, S.; Kadla, J.F. The formation of strong intermolecular interactions in immiscible blends of poly(vinyl alcohol) (PVA) and lignin. Biomacromolecules 2003, 4, 561-567. [CrossRef]

222. Lu, C.; Ford, E. Antiplasticizing behaviors of glucarate and lignin bio-based derivatives on the properties of gel-spun polyvinyl alcohol) fibers. Macromol. Mater. Eng. 2018, 303, 1700523. [CrossRef]

223. Jin, Y.; Jing, Y.; Hu, W.; Lin, J.; Cheng, Y.; Yang, X.; Zhang, K.; Lu, C. Regulation mechanism of graphene oxide on the structure and mechanical properties of bio-based gel-spun lignin/poly (vinyl alcohol) fibers. Cellulose 2021, 28, 4745-4760. [CrossRef]

224. Ma, Y.; Asaadi, S.; Johansson, L.S.; Ahvenainen, P.; Reza, M.; Alekhina, M.; Rautkari, L.; Michud, A.; Hauru, L.; Hummel, M.; et al. High-strength composite fibers from cellulose-lignin blends regenerated from ionic liquid solution. ChemSusChem 2015, 8, 4030-4039. [CrossRef] [PubMed]

225. Protz, R.; Lehmann, A.; Ganster, J.; Fink, H.P. Solubility and spinnability of cellulose-lignin blends in aqueous NMMO. Carbohydr. Polym. 2021, 251, 117027. [CrossRef]

226. Bengtsson, J.; Jedvert, K.; Kohnke, T.; Theliander, H. The challenge of predicting spinnability: Investigating benefits of adding lignin to cellulose solutions in air-gap spinning. J. Appl. Polym. Sci. 2021, 138, 50629. [CrossRef]

227. Bengtsson, J.; Jedvert, K.; Hedlund, A.; Kohnke, T.; Theliander, H. Mass transport and yield during spinning of lignin-cellulose carbon fiber precursors. Holzforschung 2019, 73, 509-516. [CrossRef]

228. Mikkila, J.; Trogen, M.; Koivu, K.A.Y.; Kontro, J.; Kuuskeri, J.; Maltari, R.; Dekere, Z.; Kemell, M.; Makela, M.R.; Nousiainen, P.A.; et al. Fungal treatment modifies Kraft lignin for lignin- and cellulose-based carbon fiber precursors. ACS Omega 2020, 5, 6130-6140. [CrossRef]

229. Ago, M.; Okajima, K.; Jakes, J.E.; Park, S.; Rojas, O.J. Lignin-based electrospun nanofibers reinforced with cellulose nanocrystals. Biomacromolecules 2012, 13, 918-926. [CrossRef] [PubMed]

230. Ago, M.; Jakes, J.E.; Johansson, L.S.; Park, S.; Rojas, O.J. Interfacial properties of lignin-based electrospun nanofibers and films reinforced with cellulose nanocrystals. ACS Appl. Mater. Interfaces 2012, 4, 6849-6856. [CrossRef] [PubMed]

231. Ago, M.; Jakes, J.E.; Rojas, O.J. Thermomechanical properties of lignin-based electrospun nanofibers and films reinforced with cellulose nanocrystals: A dynamic mechanical and nanoindentation study. ACS Appl. Mater. Interfaces 2013, 5, 11768-11776. [CrossRef] [PubMed]

232. Fang, W.; Yang, S.; Yuan, T.Q.; Charlton, A.; Sun, R.C. Effects of various surfactants on alkali lignin electrospinning ability and spun fibers. Ind. Eng. Chem. Res. 2017, 56, 9551-9559. [CrossRef]

233. Chee, P.L.; Yew, P.Y.M.; Kai, D.; Loh, X.J. Reinforcement of aligned cellulose fibers by lignin-polyester copolymers. Mater. Today Chem. 2020, 18, 100358. [CrossRef]

234. Koivu, K.A.Y.; Sadeghifar, H.; Nousiainen, P.A.; Argyropoulos, D.S.; Sipila, J. Effect of Fatty Acid esterification on the Thermal Properties of Softwood Kraft Lignin. ACS Sustain. Chem. Eng. 2016, 4, 5238-5247. [CrossRef] 